\title{
Big Data e Inteligencia Artificial
}

Una visión económica y legal de estas herramientas disruptivas 
Edita:

Autores:

Año:

D01:
Fundació Parc Científic Universitat de València

c/ Catedrático Agustín Escardino, 9

46980 Paterna (España)

Telf: +34 963544758

Correo electrónico: parc.cientific@uv.es

Andrés Pedreño Muñoz, Luis Moreno Izquierdo, Javier Plaza Penedés y María Iranzo Cabrera

2018

10.7203/PCUV-1 


\section{Índice}

Introducción

i. $\quad$ El impacto económico de la Inteligencia Artificial por Andrés Pedreño y Luis Moreno.

1. Introducción: Una nueva era para la humanidad y para los sistemas económicos ......6 6

2. La necesidad de desarrollar un potente sector de Inteligencia Artificial .................. 9

3. Impactos sectoriales de la IA: ¿transformación o disrupción? .............................13

4. IA: Talento y empleo y las imprescindibles políticas activas ................................ 16

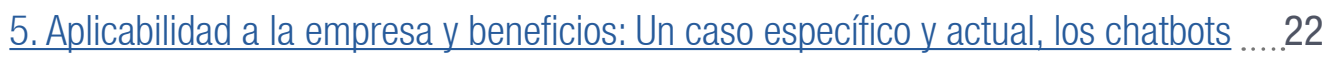

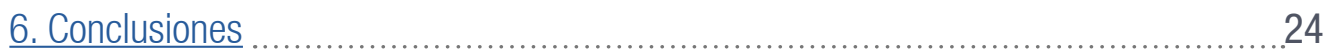

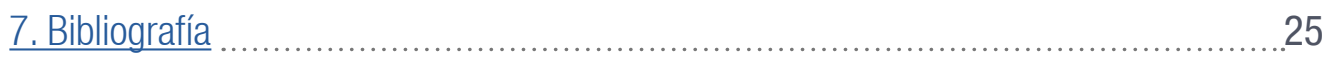

ii. $\quad$ Aspectos legales del Big Data y la Inteligencia Artificial, por Javier Plaza ................. 28

1. Una era de disrupción de la sociedad y nuestros sistemas económicos .................28

2. Principios rectores para el Big Data y la Inteligencia Artificial ............................29

3. Un marco normativo para el Big Data y la Inteligencia Artificial ..........................30

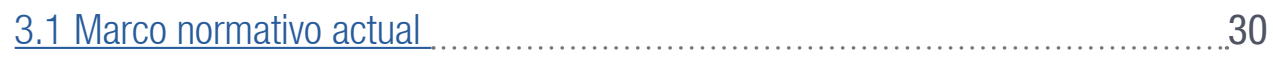

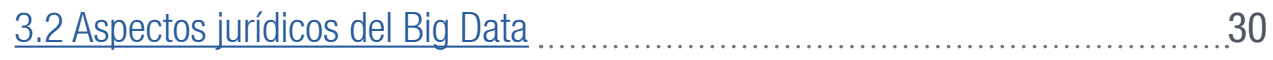

3.2.1 Marco normativo actual

3.2.2 Big Data sobre datos económicos, científicos o sociales no personales.

Concepto y alcance de la llamada "minería de textos y datos"

3.3 Aspectos jurídicos de la Inteligencia Artificial susceptibles de ser regulados

36

3.3.1 Tribunal y protección del algoritmo a través de la nueva regulación del secreto comercial o de alguna institución de propiedad intelectual 0 industrial

3.3.2 Protección de las obras intelectuales resultado de la IA

El encaje actual en el derecho de autor y en la futura Directiva comunitaria 
4. La posibilidad de considerar a los robots como entidad propia ........................ 39

$\underline{5 .}$ Responsabilidad de decisiones robotizadas / automatizadas ..............................4 41

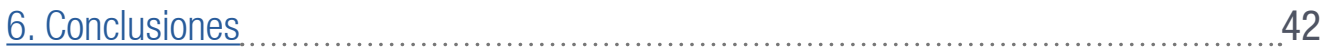

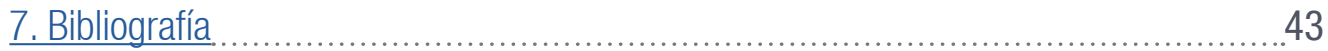

iii. Casos prácticos: Startups basadas en Inteligencia Artificial ..........................4

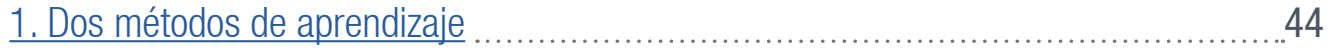

2. Machine-Learning: Santa Barbara Smart Health ........................................ 45

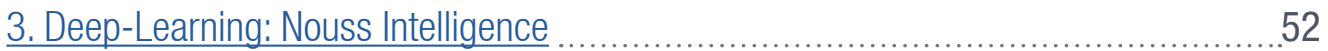




\section{Introducción}

En el camino a una industria de valor añadido, sostenible, inteligente e integradora, el Big Data y la Inteligencia Artificial (IA) son elementos clave para dotarla de una mayor eficiencia operativa y una más ágil capacidad de respuesta en diferentes ámbitos competitivos, desde el diagnóstico médico hasta el management del capital humano de una compañía, entre otros tantos.

En este contexto, el impulso a la implantación de estas dos innovaciones tecnológicas en la economía del conocimiento será un factor determinante en el futuro próximo, pues limitará las fortalezas o las debilidades de los estados.

Y, en este punto, ¿dónde está España? De momento, urgiendo la publicación del borrador del "Libro Blanco sobre Big Data e Inteligencia Artificial", en cuyo Comité de Expertos trabajan, entre otros, el economista Andrés Pedreño y el jurista Javier Plaza.

Los dos, conocedores en profundidad de estas tecnologías disruptivas, son quienes conducen el peso de este ebook, en el cual se reflexiona sobre sus aplicaciones en su vertiente económica, legal y práctica. Su aplicabilidad requiere de una estrategia y apuesta gubernamental ambiciosa y capaz de consolidar la transformación de nuestro sistema económico en el nuevo contexto internacional que se avecina.

Andrés Pedreño, Catedrático de Economía Aplicada, fue rector de la Universidad de Alicante entre 1993 y 2000, periodo en el que impulsó la constitución del primer parque científico de la Comunitat Valenciana. Hoy es Presidente de AlicanTEC, asociación sin ánimo de lucro para el desarrollo de la economía digital y los sectores de futuro, es Director del Observatorio Fintech y Director del Observatorio de Inteligencia artificial. En este libro digital se responsabiliza de explicar, junto con el profesor Luis Moreno, los impactos sectoriales de la IA así como su afectación al empleo y la aplicabilidad a la pequeña y mediana empresa.

Por su parte, Javier Plaza, Catedrático de Derecho Civil, es hoy el Delegado de Protección de Datos de la Universitat de València. Experto en protección de datos, Big Data, Inteligencia Artificial y Transparencia, aborda cuál es en estos momentos el marco normativo actual de estas dos tecnologías punteras al tiempo que avanza cuáles son los aspectos del Big Data y la IA que deben ser regulados.

Por último, se ha considerado que no es factible alardear de unos potenciales beneficios sin constatar su aplicación práctica. Con este objetivo se ha contado con la participación de dos incipientes startups que hacen uso de motores basados en IA. Se trata de Santa Barbara Smart Health y Nouss Intelligence, cuyos responsables explican en estas páginas el fundamento de su creación y los resultados de sus desarrollos. 


\title{
i. El impacto económico de la Inteligencia Artificial
}

\author{
Pedreño Muñoz, $A$. * \\ Moreno Izquierdo, L. ** \\ * Catedrático de Economía Aplicada; Exrector de la Universidad de Alicante; Impulsor de Alican-TEC \\ ** Profesor ayudante doctor Universidad de Alicante; Coordinador de UniMOOC
}

\section{UNA ERA DE DISRUPCIÓN DE LA SOCIEDAD Y DE NUESTROS SISTEMAS ECONÓMICOS}

Hace no mucho tiempo, Andrew Ng, cofundador de Coursera, profesor de Stanford y fundador del Proyecto Google Brain Deep Learning, comentó que "al igual que la electricidad transformó casi todo hace un siglo, hoy en día se me hace difícil imaginar una industria que no sea transformada por la Inteligencia Artificial (IA) en los próximos años"1. Esta frase, que ha hecho fortuna en el ámbito de la propia IA, la equiparaba con la revolución tecnológica más importante en siglos, y que supuso un input fundamental para explicar el desarrollo y funcionamiento de cualquier sistema económico. Pero... ¿exagera el profesor $\mathrm{Ng}$ ?

De entrada, es necesario advertir que, con toda seguridad, la IA marcará una nueva era para la humanidad. El concepto de IA hace mención a un conjunto de avances que hacen que las máquinas puedan aprender, razonar o comunicarse, como el aprendizaje autónomo, el Deep Learning, o el procesamiento natural del lenguaje (Neuro-Linguistic Programming, NLP), entre otros. Aunque no exista una única definición del concepto, diferentes autores han expuesto el desarrollo de la IA a partir de cuestiones tales como la racionalidad y el razonamiento, con debates acerca del comportamiento de las máquinas con un carácter lógico más cercano al comportamiento 'humano' o 'matemático', que dan una dimensión enorme al término, siempre en continua evolución, con unos registros de impacto cada vez mayores ${ }^{2}$.

De hecho, la IA está permitiendo sobrepasar los límites cognitivos de nuestra especie. Desde un punto de vista evolutivo, los seres humanos nos hemos vuelto 'incompetentes' para progresar con eficiencia y abordar problemas muy complejos, especialmente aquellos que requieran enfrentarnos al tratamiento masivo de datos o la respuesta razonada ante situaciones de estrés. Y en ese sentido, la IA ya está siendo aplicada con notable éxito en diferentes ámbitos, como en la conservación de las especies y la protección

\footnotetext{
1 Discurso pronunciado en Noviembre de 2017, dentro de las conferencias Al Frontiers.

${ }^{2}$ Véase Russell y Norvig (2016), una de las obras clave para conocer los avances metodológicos de la IA en las últimas décadas.
} 
de los ecosistemas ${ }^{3}$, la explotación de los recursos naturales ante el reto del abuso y la sobrepoblación ${ }^{4}$, las incógnitas sobre el cambio climático ${ }^{5}$, la exploración espacial y el descubrimiento de nuevas estrellas y planetas ${ }^{6}$, la comprensión de la materia (partículas, nanociencia, nanotecnología) o la predicción y superación de enfermedades complejas como el cáncer ${ }^{7}$, entre otras muchas.

La aplicación de la IA está mejorando cuantitativa y cualitativamente el resultado que los seres humanos pudiéramos obtener basándonos en la observación o la aplicación de soluciones aprendidas para la resolución de problemas. En otras palabras, nuestra especie ha asumido nuestras limitaciones intelectuales, por lo que destinamos nuestro tiempo y esfuerzo en crear entidades inteligentes que superen las fronteras que nos marca nuestro propio cerebro.

Por supuesto, la Inteligencia Artificial está aún en una fase inicial, pese a que su desarrollo comenzara entre los años 40 y 50 del siglo XX, siendo desde entonces una de las áreas en la que los científicos se han encontrado más interesados por su aplicación completamente transversal. Así pues, durante las próximas décadas la aplicación de los avances en torno a la IA seguirá proporcionando progresos muy significativos, y los científicos de datos seguirán aportando nuevas capacidades para afrontar con éxito la mayoría -por no decir todos- de los retos más importantes de nuestro futuro como especie y para la protección de nuestro planeta.

Llegados a este punto, la aproximación de Andrew $\mathrm{Ng}$ de la IA a la electricidad puede no resultar tan exagerada, pues se pone en juego la capacidad de nuestros sistemas económicos de acometer una profunda transformación global y sectorial. Lejos de preverse una transición tranquila, los expertos nos hablan de una rápida aceleración en los próximos años dadas las ventajas de competitividad que supondrán para los pioneros. Pero incluso más allá del impacto económico -que veremos más adelante-, la IA está adentrándose en campos que se creían hasta la fecha meramente cuestiones humanas, como el arte, la ciencia o la creatividad.

\footnotetext{
${ }^{3}$ Entre otros muchos ejemplos, se pueden citar obras como Godow y Peterson (2000), que emplean metodologías de IA para predecir el movimiento geográfico de las aves y garantizar su protección; Nijkamp y otros (2008), quienes hacen uso de un modelo económico basado en la IA para estimar el coste y rentabilidad de la conservación de la biodiversidad de los ecosistemas; o más recientemente Di Minin y otros (2018), que con IA rastrean redes sociales en busca del comercio ilegal de animales salvajes.

${ }^{4}$ Coulson, Folse y Loh (1987), Varis y Kuikka (1999) o Ducrot y otros (2004), entre muchas otras investigaciones, han tratado la gestión y explotación de los recursos en la naturaleza y las ciudades a partir de metodologías propias de la IA, con especial atención a la satisfacción de las necesidades de una población humana creciente.

${ }^{5}$ Entre otras cuestiones, se han tratado las previsiones futuras de lluvias en todo el planeta (Tripathi y otros, 2006), la adaptación futura de las especies y el cambio en la biodiversidad derivadas del cambio climático (Peterson y otros, 2002; Peterson 2003).

${ }^{6}$ El equipo de IA de la NASA aporta una gran información acerca del empleo de esta tecnología en sus descubrimientos. El envío de robots de exploración planetaria (Chien y Wagstaff, 2017), la gestión automatizada de sondas y telescopios espaciales (Troesch, Chien y Ferguson, 2017) o el tratamiento de las grandes bases de datos generadas por satélites, telescopios, etcétera (Perez-Ayucar y otros, 2016), entre otras prácticas, serían hoy en día imposibles sin la IA.

${ }^{7}$ En trabajos como Quaglini, Brahona y Andressen (2001), Patel y otros (2009), o más recientemente en Hamet y Tremblay (2017), se hace un resumen de la importantísima evolución de la IA en la medicina desde hace décadas, poniendo ejemplos de cómo la IA permite la detección y tratamiento de todo tipo de enfermedades gracias a la evaluación temprana o la elección de los tratamientos más adecuados en dosis menos perjudiciales.
} 
Con la IA cualquier capacidad humana se está robusteciendo hasta límites impensables, y constata que a fecha de hoy no somos capaces de predecir la capacidad de aprendizaje de las máquinas que creamos. Hace no mucho un equipo de investigación nos sorprendía con un cuadro de Rembrandt pintado "artificialmente" que los expertos no conseguían diferenciar de la obra original del autor barroco. También se ha demostrado que la IA es capaz de ganar a los mejores jugadores de póker del mundo aprendiendo de ellos o escribir guiones. O más importante todavía, se han desarrollado máquinas con una mayor capacidad de asimilar literatura científica y plantear nuevas hipótesis y descubrimientos que los propios científicos, como el superordenador KnIT desarrollado por IBM y el Baylor College of Medicine de Houston ${ }^{8}$, capaz de leer toda la literatura científica de un área de conocimiento en apenas horas y hacer planteamientos completamente novedosos.

Por tanto, la IA nos impone encima de la mesa una "agenda" muy ambiciosa y de mayor entidad de lo que hasta la fecha suponían cuestiones como la innovación, la transformación digital, la digitalización o incluso la disrupción. Ni siquiera es una mera revolución, sino más bien una reinvención, donde caben algunos atributos importantes que ya empiezan a acontecer, pero que se acelerarán en los próximos años:

1. Un cambio en los paradigmas de la propia computación y los sistemas digitales en torno a los que hemos construido plataformas, productos y servicios.

2. La creación y destrucción masiva y acelerada de empleos tradicionales. A medio plazo la necesidad de redefinir el propio concepto de empleo, con desajustes y brechas importantes en el mercado laboral.

3. Una "reinvención" de gran parte de los sectores económicos de importancia vital en nuestras economías.

4. La capacidad de generar servicios muy personalizados masivamente y cada vez más precisos en la satisfacción de necesidades específicas, incluso y especialmente en ámbitos tan complejos como la salud o la educación.

5. La necesidad de conformar ecosistemas tecnológicos donde el talento, la internacionalización y la integración de los componentes del ecosistema son fundamentales.

\section{La IA nos impone encima de la mesa una "agenda" muy ambiciosa y de mayor entidad de lo que hasta la fecha suponían cuestiones como la innovación, la transformación digital, la digitalización o incluso la disrupción.}

\footnotetext{
${ }^{8}$ Véase Spangler y otros (2014).
} 
Por tanto, y asumiendo la importancia de la IA en el desarrollo futuro de la sociedad y de la economía global, debemos cuestionar si nuestros gobernantes son conscientes o suficientemente proactivos para afrontar la entidad de los cambios y retos asociados a esta nueva revolución. Y si, siendo conscientes, las estrategias elegidas son acertadas para afrontar todas las potencialidades, riesgos y beneficios que la IA nos puede proporcionar. En los siguientes puntos, veremos precisamente cómo se están preparando los países ante los nuevos cambios que se avecinan, así como la necesidad de tomarse muy en serio acciones que eviten una pérdida competitiva sin precedentes para Europa a lo largo de este siglo.

\section{LA NECESIDAD DE DESARROLLAR UN POTENTE SECTOR DE INTELIGENCIA ARTIFICIAL}

A pesar de lo obvio que pueda resultar este apartado en función de lo comentado en nuestra introducción, es necesario incidir en una imperiosa necesidad de desarrollar estrategias que potencien la IA en las economías. Sobre todo si comparamos la situación existente entre diferentes países, con bloques bien definidos donde Estados Unidos y China se confirman como potencias destacadas, y con una Unión Europea rezagada, que lejos de sumarse al carro se permite incidir en errores históricos que muestran preocupantes signos de debilidad, como la carencia de un mercado digital único, la inexistencia de unicornios digitales relevantes, estrategias aisladas de los países que no aprovechan el marco único europeo, restricciones a la explotación de datos, o el "Brexit", que supone la salida de la economía digital por excelencia de la UE. De hecho, las primeras previsiones ya nos sitúan un escenario en el que la región Asia Pacífico liderará Ios rendimientos derivados de la IA, seguida de Norteamérica y, a mayor distancia, por Europa (Ver "Gráfico 1. Rendimientos empresariales derivados de la IA por regiones (2015-2024) (en millones de dólares)” en la página 9).

\section{GRÁFICO 1. RENDIMIENTOS EMPRESARIALES DERIVADOS DE LA IA POR REGIONES (2015-2024) (EN MILLONES DE DÓLARES)}

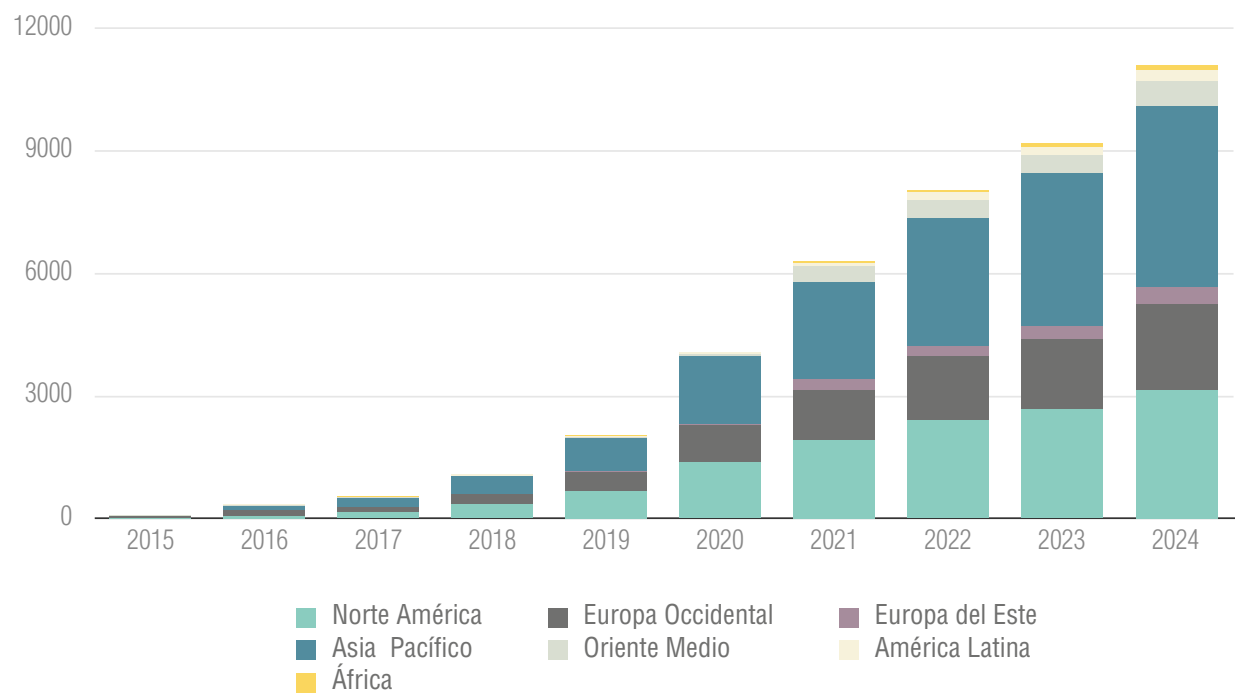

Fuente: Tráctica 
Por su parte, Estados Unidos y China han destacado desde muy temprano en identificar los grandes temas y diseñar ambiciosas estrategias. El informe creado por la Casa Blanca en el último año de mandato de Barack Obama, Preparing for the Future of Artificial Intelligence ${ }^{9}$, ponía sobre aviso a la economía mundial de la decidida apuesta estadounidense por liderar la tecnología clave de las próximas décadas, que incluía propuestas tales como invertir 4.000 millones de dólares en la investigación de vehículos autónomos y limpios, la inversión directa de más de 1.200 millones en tecnologías relacionadas con la IA por parte del gobierno, el liderazgo militar -mención especial a los drones-, así como destinar parte de la inversión en I+D realizada por National Institutes of Health $(\mathrm{NIH})$, el Departamento de Empleo o el de Educación en la mejora de sus áreas gracias a la IA.

Esta propuesta, no obstante, ha sido superada en la praxis gracias a la apuesta del sector tecnológico estadounidense, con especial relevancia de las empresas del famoso Silicon Valley. A escala global, se estima que el gasto en investigación y desarrollo de IA de los gigantes tecnológicos supera ampliamente los 20 mil millones de dólares. Cualquier empresa tecnológica que pensemos (Google, Amazon, IBM, Microsoft, Uber, Netflix, eBay, Airbnb...) cuenta con departamentos de IA. Pero, además de su propio desarrollo, debemos sumar las adquisiciones de terceras empresas. Por ejemplo, Google ha adquirido startups especializadas en IA por más de 4.000 millones de dólares desde 2006, Amazon ha invertido casi mil millones y Apple está cerca de los 800 millones de dólares.

Todo ello coloca a Estados Unidos, sin lugar a dudas, como el principal motor de la IA del planeta, y a San Francisco en el gran hub mundial (Ver "Gráfico 2. Distribución global de Startups de Inteligencia Artificial (países y hubs)” en la página 11). Sin embargo, China no piensa en mantener su segunda posición, sino que ya ha anunciado acciones de enorme calado para dominar la industria de la IA en la próxima década. Gracias al apoyo del gobierno chino, que invierte miles y miles de millones de dólares en el desarrollo de centros de investigación, capital humano y parques tecnológicos, las empresas chinas de IA consiguieron en 2017 mayor financiación que las estadounidenses de acuerdo al estudio realizado por $\underline{\text { CBInsights }}$ (Ver "Gráfico 3. Distribución de la inversión global en la creación de startups de IA en 2017" en la página 11). Aunque en valores absolutos el número de empresas dedicadas a la IA es muy superior en Estados Unidos, China ya lidera la publicación total de patentes y artículos científicos, con una apuesta en tecnologías de reconocimiento facial, chips para la IA y productos que usan Deep Learning en su funcionamiento.

En total, entre Estados Unidos y China se repartieron el 86\% de los más de 15.000 millones de dólares destinados globalmente para la creación de startups de IA, una muestra de esta hegemonía de los dos gigantes económicos a nivel mundial.

¿Y qué ocurre en el resto del mundo? Como ya aventuramos, Europa parece estar atónita ante el imparable crecimiento de China y Estados Unidos. Lejos de converger, estamos en una etapa en la que los dos líderes, en su afán por liderar la IA, seguirán mar-

\footnotetext{
${ }^{9}$ El informe puede descargarse en la web https://obamawhitehouse.archives.gov. Incluye, además un Plan estratégico de desarrollo e investigación en inteligencia artificial.
} 

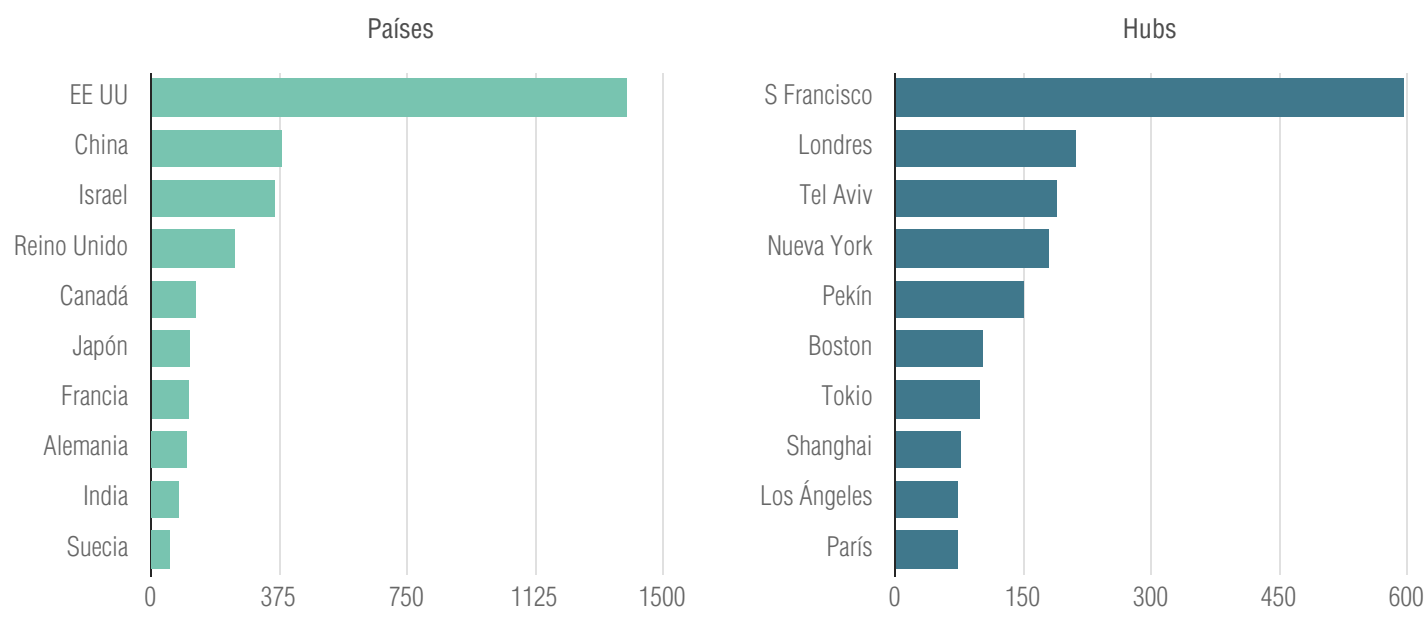

Fuente: Asgard y Roland Berger

GRÁFICO 3. DISTRIBUCIÓN DE LA INVERSIÓN GLOBAL EN LA CREACIÓN DE STARTUPS DE IA EN 2017

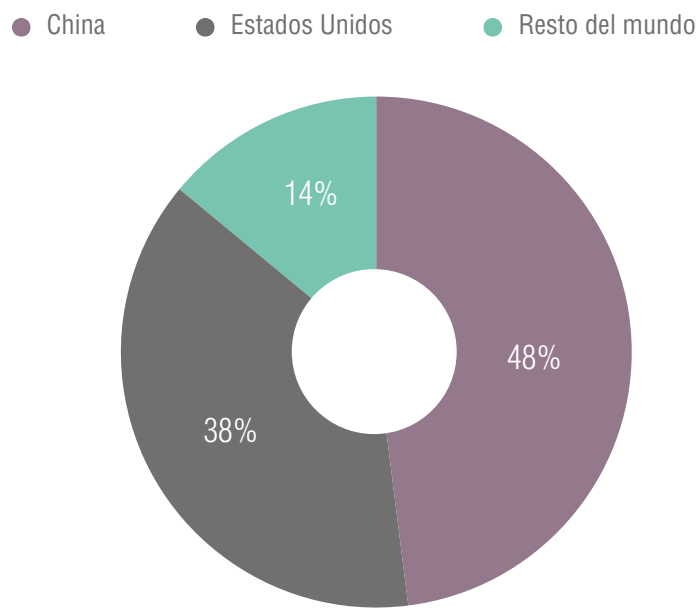

Fuente: Informe "Top Al Trends To Watch In 2018" elaborado por $\underline{\text { CBInsights. }}$

cando una distancia abismal con respecto a los demás países. Ante esta situación, entre 2017 y los seis primeros meses de 2018 multitud de países comenzaron a hacer sus deberes y trazaron líneas de actuación para obtener una mayor relevancia. Nos referimos a Canadá, Dinamarca, Japón, Finlandia, México, India, Corea del Sur, Italia, la Comisión Europea, Francia, la región nórdico-báltica, Singapur, Suecia, Taiwán, Kenia, los Emiratos Árabes Unidos, Australia, Egipto o el Reino Unido. Entre ellos, no se encontraba España (Ver "Imagen 1. Estrategias nacionales de Inteligencia Artificial" en la página 12).

Sin embargo, algunos de los países que políticamente se han apuntado al carro de la IA recientemente parecen hacerlo más por obligación que por convicción. Esto se percibe 


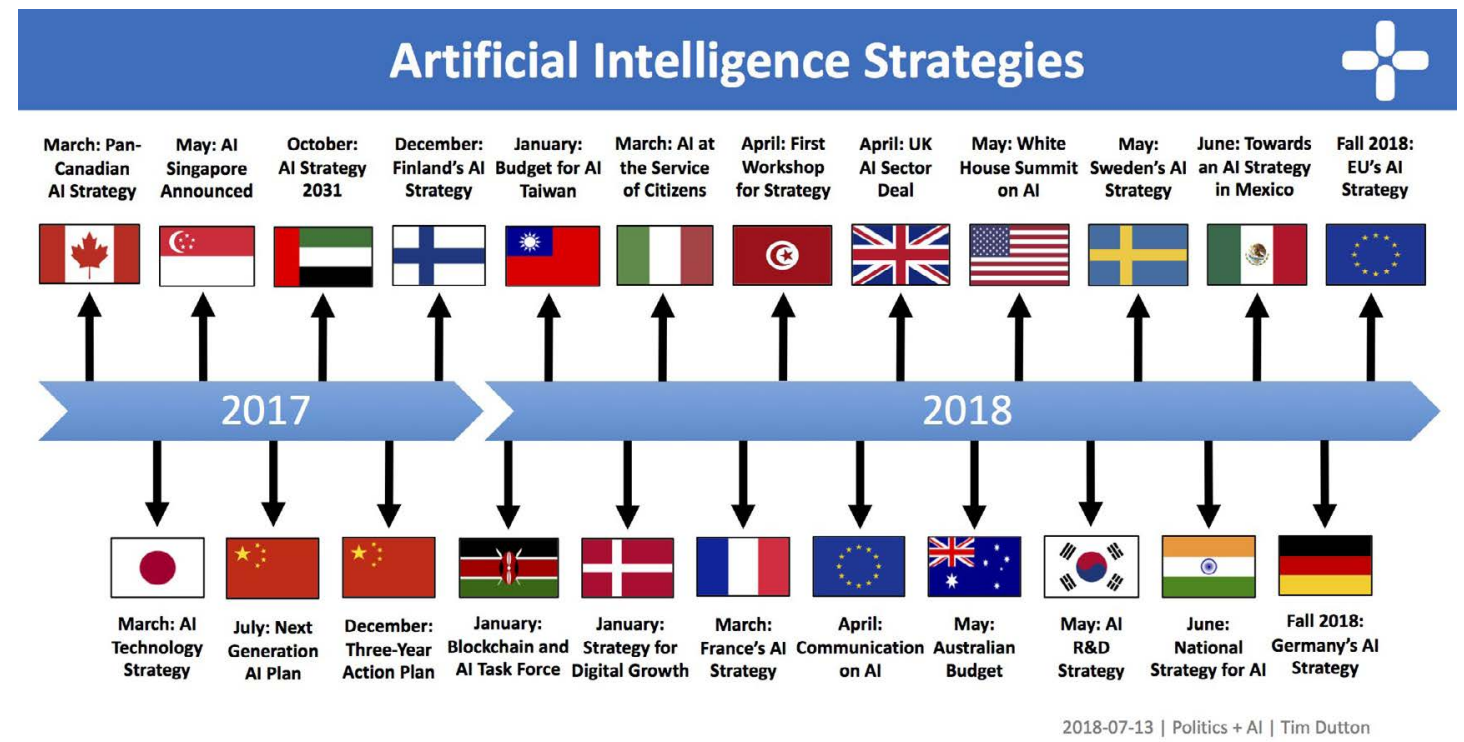

Fuente: Dutton, T (2018, 28 de junio). An Overview of National Al Strategies. Medium.

Recuperado de https://medium.com/politics-ai/an-overview-of-national-ai-strategies-2a70ec6edfd

claramente tanto en las apuestas presupuestarias como en el contenido de los temas que son objeto de estrategia o apuesta.

En el caso de la UE, por ejemplo, su mercado fragmentado será un impedimento para el desarrollo de estrategias de éxito en IA, con diferencias enormes entre los países del centro y norte del continente, y los mediterráneos y del este ${ }^{10}$.

En un entorno sin claros referentes europeos como puede ser Silicon Valley (y en menor medida Boston) en Estados Unidos, o el eje Pekín-Shenzhen en China, que aglutinan universidades y empresas, las ayudas europeas anunciadas (20 mil millones de euros entre 2018 y 2020 para la creación de empresas, la formación de talento, etcétera) pueden no ser del todo efectivas ${ }^{11}$. En Europa, Londres es el verdadero referente como hub consolidado de empresas de IA, con un sector fintech robusto y prestigiosas universidades como Cambridge, London School of Economics y Oxford en un radio de 100 kilómetros, además de los planes de inversión gubernamentales, que prevén un esfuerzo de más de mil millones de dólares destinados a la industria de la IA. Los pasos dados hasta la fecha parecen confirmar que ante un panorama incierto como el brexit a la vuelta de la esquina, Reino Unido incorpora en su agenda la economía digital y la IA como vías prioritarias para superar cualquier desventaja de su salida de la Unión Europea, liderando por delante de ésta los sectores del futuro.

\footnotetext{
${ }^{10}$ Ver el informe "Artificial Intelligence - A strategy for European startups", desarrollado por Asgard y Roland Berger.

${ }^{11}$ De forma resumida, puede verse la agenda europea de inversión en Inteligencia Artificial en la web de la Comisión Europea, donde se especifica la cantidad de inversión que irá a parar a cada sector: ec.europa.eu/digital-single-market/en/ news/factsheet-artificial-intelligence-europe
} 
Por su parte, Francia y Alemania, empiezan a desarrollar planes muy ambiciosos que incluso pueden llevarles a trabajar de forma conjunta. Esta estrategia debe consolidarse en los próximos años, sobre todo tras la salida del Reino Unido de la Unión Europea, que los dejará como únicos referentes de nuestro entorno. Para ello, los dos gobiernos han preparado sendas hojas de ruta que les llevará a invertir 1.500 millones de euros en el desarrollo de IA en sus países, lejos, muy lejos, de los 4.000 millones anunciados por Estados Unidos (sin contar a sus gigantes tecnológicos), pero necesarios para el despegue de la tecnología en Europa. Sin embargo, parten con un retraso evidente en materia de Inteligencia Artificial comparado con otros países, no solo Estados Unidos o China.

Israel, por ejemplo, es el país con el mayor número de startups por habitante dedicadas a la IA del mundo por habitante, con un hub tecnológico muy potente en Tel-Aviv y una orientación que va más allá de cuestiones militares -aunque el ejército es sin duda uno de los motores fundamentales para su implantación-, como los vehículos autónomos. O Canadá, que busca ser líder en IA atrayendo talento gracias a un ambicioso plan nacional (Pan-Canadian Artificial Intelligence Strategy) impulsado directamente desde la propia convicción de la presidencia del gobierno.

Respecto a España, podemos ya hablar de una situación preocupante, sin un plan estratégico definido respecto a la IA, y sin un ecosistema tecnológico relevante que permita el desarrollo sistemático de empresas innovadoras. En este contexto España tiene planteado un borrador de "Libro Blanco sobre Big Data e IA" que, aparte de la urgencia de su publicación, debe plasmarse en una estrategia y apuesta gubernamental ambiciosa y capaz de consolidar el liderazgo y transformación de nuestro sistema económico en el nuevo contexto internacional que se avecina.

Si un país quiere ser relevante en este sector fundamental tiene que aspirar a crear su propio "ecosistema" en torno a la IA, muy integrado internacionalmente con los líderes en estos campos. Incluso China, que pretende liderar este campo a escala global, habla de "la necesidad de una colaboración global"12. Pero, aun así, hay y habrá una competición brutal para la captación de talento, fundamental para la investigación, el desarrollo de capital humano, la generación de empresas relevantes, la generación de habilidades y educación o la rápida adopción de innovaciones y tecnologías IA en el sector público y privado... Además de, tener ideas claras sobre la ética e inclusión, normas y regulaciones, e infraestructura digital y de datos.

\section{IMPACTOS SECTORIALES DE LA IA: ¿TRANSFORMACIÓN O DISRUPCIÓN?}

En el corto plazo, los países empezarán a plantear mediante sus planes nacionales si pretenden ser una potencia en la IA en cualquiera de sus áreas (como Estados Unidos

\footnotetext{
${ }^{12}$ Ver noticia publicada por MIT Technology Review el 5 de Abril de 2018: "China quiere dominar la IA pero con apoyo del resto del mundo". Recuperado en: technologyreview.es/s/10099/china-quiere-dominar-la-ia-pero-con-apoyo-del-restodel-mundo
} 
o China), o si prefieren especializarse en algunas vertientes concretas donde tenga ventajas competitivas (vía talento, datos, demanda para la transformación sectorial,...). Las estrategias que adopten serán decisivas, ya que no se podrá obviar la necesidad de asimilar la transformación sectorial y las ganancias de competitividad que la IA propicia y propiciará. Quedarse fuera de juego no es una opción.

Aun así, existen dos estrategias. La primera, sería asimilar la transformación mediante la importación e incorporación (de forma más o menos eficiente) de tecnologías IA a nuestras empresas y procesos productivos, especialmente si somos objeto de disrupción a través de nuevas empresas que plantean a nuestros consumidores nuevas fórmulas de productos y servicios más ventajosos y competitivos.

La segunda opción, sin duda más acertada, es la de actuar como "disruptores", mediante una especialización temprana en IA. En un entorno como España, donde no se cuenta con ninguna región líder en innovación a nivel europeo ${ }^{13}$, puede resultar difícil hacer una apuesta global por liderar el panorama de la IA, pero qué duda cabe de que tiene todas las herramientas y mecanismos necesarios para ser un jugador relevante en sectores clave como la construcción, el turismo, la banca, la sanidad, la industria de la moda, e incluso, el fútbol. No obstante, la línea que separa el ser "disruptores" del ser "disruidos" pasa por una estrategia ambiciosa y temprana en torno a la IA, una masa crítica educada en el entorno digital, un sector productivo que apueste por la innovación y con acceso a la financiación, y la captación de talento, que puede ser incluso más importante que la propia retención.

Aunque desde hace tiempo se asume que la IA marcará un antes y un después en casi todos los sectores, a día de hoy se puede hacer grandes diferencias según su incorporación (Ver "Gráfico 4. Adopción de IA por sectores." en la página 15): aquellas industrias que adoptaron rápidamente y de forma profunda esta tecnología (empresas tecnológicas y de telecomunicaciones, la industria automovilística o el sector financiero), las que están en proceso intermedio de incorporación (el comercio y la logística, los medios y la industria alimentaria) y las que están comenzando a aplicar IA (la educación, la atención médica, la construcción o el sector turístico, por ejemplo). Precisamente, en estos sectores que aún requieren madurar la incorporación de IA es donde España podría tener un papel relevante, dado que cuenta con un público suficiente como para potenciar su desarrollo en base a la interacción con la demanda y el uso masivo de datos.

El desarrollo de tecnologías de aprendizaje autónomo, robótica o agentes virtuales inteligentes, por ejemplo, podrían tener un impacto de gran calado en los sectores que tradicionalmente han marcado el crecimiento de nuestra economía. En el caso del turismo, por ejemplo, podríamos ayudarnos de la IA para anticiparnos a la demanda turística (intereses, expectativas, opiniones,...); para ofrecer productos de mayor rentabilidad; o

\footnotetext{
${ }^{13}$ Atendiendo al Regional Innovation Scoreboard elaborado por la Comisión Europea en 2018, solo Euskadi puede reconocerse como una región fuertemente innovadora, seguida de Madrid y Cataluña (estas dos últimas, como moderadamente innovadoras). Ninguna región española está ni siquiera cerca de ser una líder en innovación. Los diferentes informes relativos a innovación regional, tanto a nivel europeo como por países, pueden descargarse en: ec.europa.eu/ growth/industry/innovation/facts-figures/regional_en
} 
con el desarrollo de destinos inteligentes que permitan una mejor convivencia y disfrute de los entornos atractivos de las ciudades para turistas y residentes. El sector de la construcción puede nutrirse de la combinación entre IA, internet de las cosas (domótica) e impresoras 3D para reducir costes en la construcción y modernizando el parque actual de viviendas. También la educación se servirá del Machine Learning para el desarrollo de planes formativos más adaptados a la oferta laboral; y la adopción temprana de inteligencia artificial en combinación con tecnologías como Distributed Ledger (DLT) - - si se prefiere Blockchain- en la banca española podría impulsar una nueva era de liderazgo europea y mundial de nuestro sector.

\section{GRÁFICO 4. ADOPCIÓN DE IA POR SECTORES.}

Trayectoria de demanda futura de IA

$\%$ de cambio estimado en el gasto en IA en los próximos tres años, ponderado por el tamaño de las empresas.

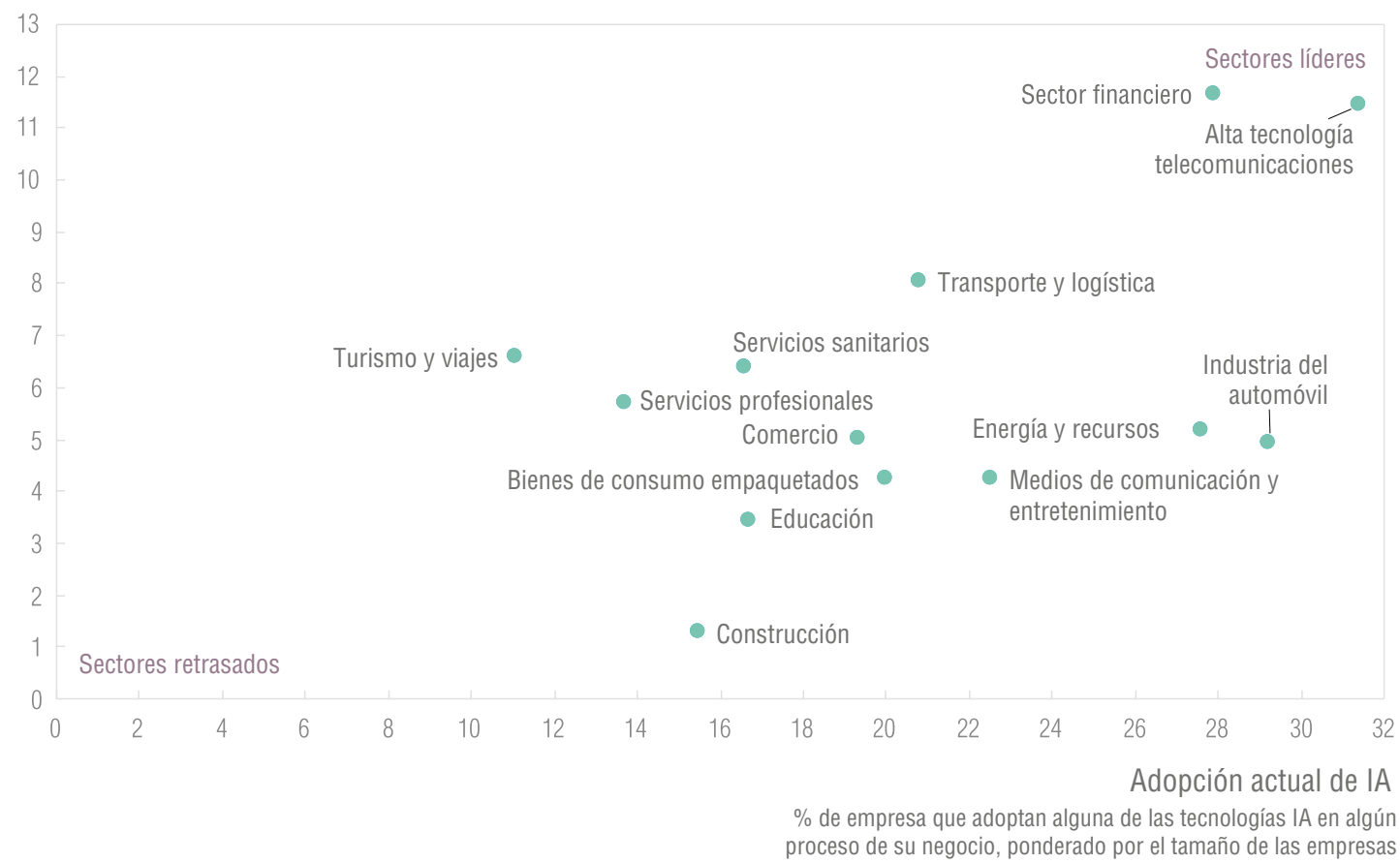

Fuente: Informe "Artificial Intelligence. The next digital frontier?". Mackinsey Global Institute.

Las anteriores son solo algunas cuestiones que ya están sobre la mesa con los desarrollos actuales sin más ambición que servir de ejemplo de la necesidad y ventajas de la adopción de IA por nuestras industrias. Sin embargo, hacer un catálogo de impactos sectoriales excedería la extensión de este capítulo y además quizás tuviera una vigencia muy efímera.

De todo ello, sin embargo, es importante rescatar que la IA y su hibridación de otros desarrollos tecnológicos como Internet de las Cosas (IoT), Blockchain, Big Data, Computación Cuántica, Robótica, Impresión 3D,... todavía potenciarán muchos más cambios y transformaciones de todos nuestros sectores. A este conjunto de tecnologías podríamos llamarles como las "grandes disruptoras", contestando así a la pregunta que nos hacíamos al principio de este apartado: la IA es, sin duda, una disrupción tecnológica casi sin precedentes, pero no es la única. 
Vivimos en la era del conocimiento, y es precisamente la apuesta por la innovación la que está permitiendo dar los mayores pasos tecnológicos al ser humano, desde la agricultura de precisión y la gestión de los recursos naturales, pasando por la dotación de inteligencia a nuestras ciudades y casas, hasta la automatización de los procesos industriales, los servicios y los transportes. En una década, quizá ni siquiera la sanidad o los sistemas educativos, con tradiciones que han perdurado siglos y siglos, se parecerán bien poco a los que conocemos en la actualidad.

\section{IA: TALENTO Y EMPLEO Y LAS IMPRESCINDIBLES POLÍTICAS ACTIVAS}

Si hay un componente vital para una estrategia efectiva en torno a la IA es la atracción y desarrollo del talento. Y si hay una variable que soportará y escenificará una gran parte de la disrupción esa es el empleo.

A lo largo de los últimos años se han llevado a cabo diversos estudios y algunas cuantificaciones para identificar el impacto de la IA en el empleo neto de los diferentes países. Quizás casi todos adolezcan de deficiencias e inconsistencias notables ante la falta de datos públicos, pero se pone de relieve la enorme "convulsión" que afectará al mercado de trabajo durante los próximos años.

Estas dudas que actualmente nos asaltan sobre cómo la robótica o la automatización derivada de la Inteligencia Artificial afectarán al empleo no son nuevas y ya en 1984 Nils J. Nilsson, uno de los investigadores más relevantes en el campo de la inteligencia

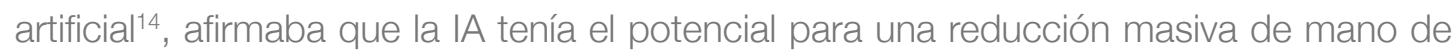
obra humana, siendo las personas prescindibles en un futuro para la producción de bienes y servicios. El autor, sin embargo, y pese a comprender el miedo de la sociedad a una pérdida generalizada de puestos de trabajo, entiende los avances en IA como una "bendición", y no como una "maldición" (Nilsson, 1984: 6), que nos permitirán una vida mejor dedicándonos a lo que nos gusta, y no a nuestros empleos. Ya en la actualidad, el debate sobre una renta básica universal debido a la destrucción de empleo se ha convertido en una idea reincidente. Tecnólogos y empresarios con tanta trayectoria como Elon Musk ${ }^{15}$, Mark Zuckerberg ${ }^{16}$ o Andrew Yang ${ }^{17}$, entre otros, se han pronunciado advirtiendo la necesidad de trazar planes que garanticen el bienestar de los ciudadanos

\footnotetext{
${ }^{14}$ Entre otros méritos, es profesor emérito en Ciencias de la Computación en la Universidad de Stanford, habiendo sido director del mismo departamento durante cinco años. También es uno de los miembros fundadores y ex-presidente de la prestigiosa Asociación Americana para la Inteligencia Artificial, y uno de los mayores divulgadores de IA del mundo gracias a su labor como escritor y editor en varias revistas científicas.

${ }^{15}$ Elon Musk es uno de los referentes tecnológicos más influyentes del siglo XXI, fundador de Zip2 y uno de los creadores de Paypal, ambas adquiridas por grandes empresas tecnológicas. Actualmente es CEO de SpaceX, Tesla y Neuralink. Es también co-fundador de OpenAl, proyecto sin ánimo de lucro para acercar a la sociedad la Inteligencia Artificial.

${ }^{16}$ Mark Zuckerberg es conocido por ser el fundador y CEO de la red social Facebook, una de las empresas referentes en Inteligencia Artificial del mundo. Además, es fundador del proyecto internet.org, que busca garantizar el acceso a Internet como derecho universal.

${ }^{17}$ Andrew Yang es un conocido emprendedor estadounidense, creador de Founder of Venture y con una carrera digital muy vinculada a proyectos filantrópicos. Es actualmente candidato a presidir el partido Demócrata para las elecciones de 2020, y entre sus promesas electorales está garantizar una renta básica universal para los ciudadanos estadounidenses.
} 
durante la transición de nuestros mercados laborales hacia un modelo de automatización masiva.

Aunque este tipo de predicciones puedan resultar lejanas en el tiempo, existen varios informes y estudios publicados hasta la fecha que nos advierten de profundos cambios en el empleo y en el modelo productivo a escala global en los próximos años. Por ejemplo, las estimaciones del informe "What's now and next in analytics, Al and automation"18, realizado por Mckinsey Global Institute para 46 países, hablan de la desaparición de la mitad de los tipos de empleo presentes solo con las tecnologías existentes en la actualidad. Sin duda, los países más afectados serían aquellos que cuentan con un mayor volumen de industrias tradicionales o servicios muy escalables pero intensivos en mano de obra (como China, Brasil, Rusia, India, México, o Italia, entre otros) (Ver "Gráfico 5. Porcentaje de actividades que pueden ser automatizadas por el uso de nuevas tecnologías" en la página 17). Estos resultados concuerdan con la investigación realizada por Osborne y Frey (2017), que estimaron que el 47\% de los empleos en Estados Unidos estaban en riesgo de ser sustituidos por procesos automatizados en las próximas dos décadas por tecnologías ya existentes.

GRÁFICO 5. PORCENTAJE DE ACTIVIDADES QUE PUEDEN SER AUTOMATIZADAS POR EL USO DE NUEVAS TECNOLOGÍAS

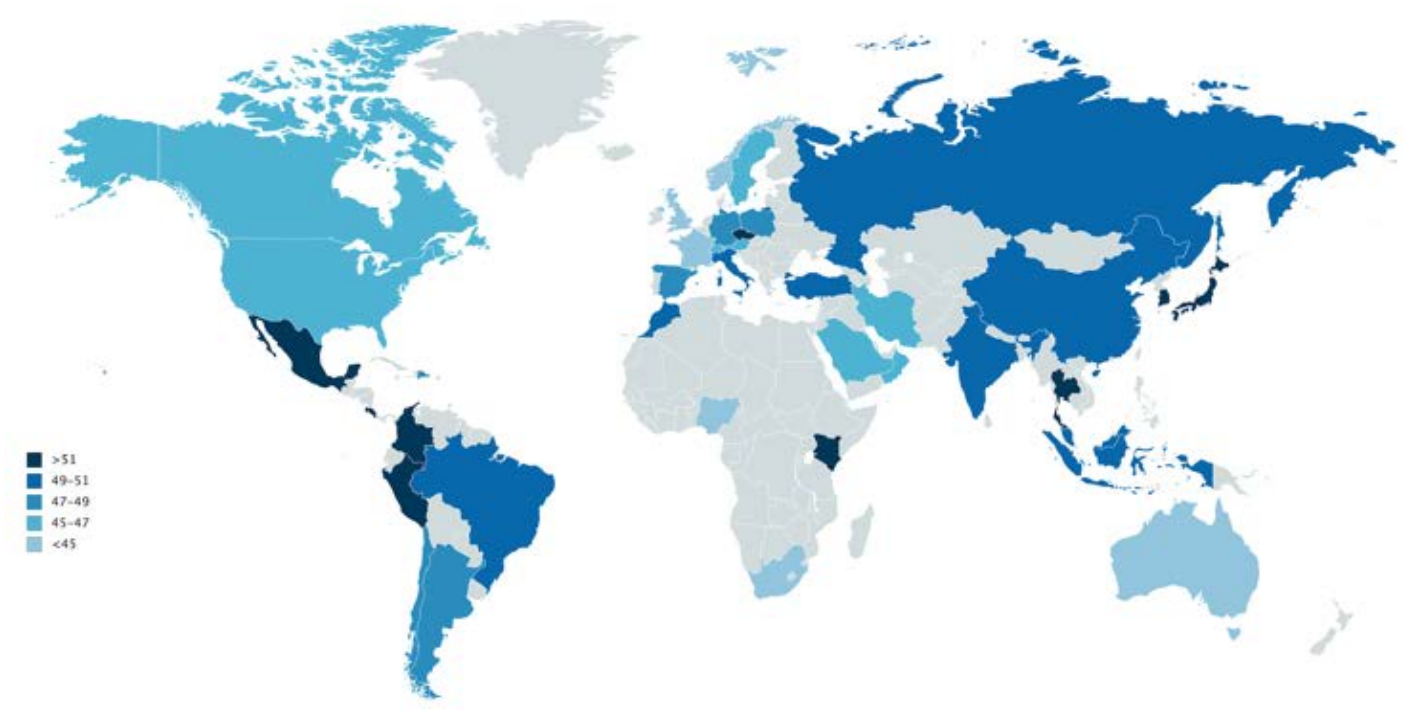

Fuente: Informe "What's now and next in analytics, Al and automation". Mckinsey Global Institute.

\footnotetext{
${ }^{18}$ Disponible en: mckinsey.com/featured-insights/digital-disruption/whats-now-and-next-in-analytics-ai-and-automation
} 
Por su parte, el informe "The macroeconomic impact of artificial intelligence"19 realizado por PwC habla de cifras netas de empleo -no de tipos de actividades-, con datos igualmente llamativos. Estados Unidos y los países más avanzados de Europa estarán en disposición en 2030 de provocar una disrupción en sus mercados laborales, con especial atención a la posibilidad de destrucción de empleo en áreas como "Transporte y logística" (hasta un 70\% de las actividades en riesgo en Estados Unidos, más de un 50\% en Europa), o la "Construcción" (un 40\% del tipo de actividades en riesgo tanto en Estados Unidos como en Europa). El resto de regiones seguirán los mismos pasos según vayan teniendo acceso a la tecnología.

Sin embargo, todos los avances en la historia del ser humano y las grandes disrupciones tecnológicas, como lo son la IA o el resto de tecnologías comentadas anteriormente, no serán una excepción. La clave estará en las políticas gubernamentales que pongan el foco en las nuevas oportunidades de empleo ligadas a este tipo de tecnologías, así como a la reconversión de empleos. Hoy por hoy lo que ya sabemos es que hay un enorme déficit mundial en torno a los ingenieros de computación y sus equivalentes. Y pese a esta previsión desde hace años, pocos países están poniendo remedio a esto. La IA aplicada, por ejemplo, a la medicina generará nuevos empleos inexistentes hoy, al igual que los propició la industrialización o la tercerización de las economías. Las tecnologías de las que hablamos generan un gran excedente en términos de productividad y esta es la clave de la que se debe partir.

El trabajo realizado por Arntz, Gregory y Zierahn (2016) para la OCDE ${ }^{20}$, además de rebajar más de 30 puntos porcentuales la destrucción de puestos de trabajo por la automatización respecto a los documentos antes citados, habla del impacto positivo también en el empleo de la IA y las tecnologías que hemos definido como "disruptoras", aunque con matices. Sin lugar a dudas, ante cambios tan drásticos como los que vivirán nuestras economías, los profesionales deberán saber adaptarse y, sin lugar a dudas, aquellos con menor nivel de educación o con especializaciones muy alejadas de la evolución tecnológica a la que asistimos estarán ante un mayor riesgo de pérdida de empleo o de reducción drástica de salarios.

\section{Aquellos con menor nivel de educación o con especializaciones muy alejadas de la evolución tecnológica a la que asistimos estarán ante un mayor riesgo de pérdida de empleo o de reducción drástica de salarios}

Estas evidencias nos conducen por tanto a seguir enfatizando en dos cuestiones fundamentales que ya expusimos en la introducción. En primer lugar, la apuesta decidida por sectores tecnológicos y la construcción de ecosistemas que permitan a nuestras empresas crecer y posicionarse competitivamente a escala global. En segundo lugar, la generación de empleo, ya que no cabe duda de que en la actualidad el sector digital es

\footnotetext{
${ }^{19}$ Disponible en: pwc.co.uk/economic-services/assets/macroeconomic-impact-of-ai-technical-report-feb-18.pdf

${ }^{20}$ Disponible en: https://doi.org/10.1787/5j|z9h56dvq7-en
} 
el de mayor dinamismo económico, y es evidente que aquellas economías con fuertes apuestas en IA y las "grandes disruptoras" exportarán tecnología y productos de alto valor, siendo las primeras en generar nuevos empleos derivados de los procesos de transformación digital.

De hecho, esta tendencia es ya palpable, y desde hace años. La Comisión Europea reclama a los países una apuesta decidida por la educación en digital para cubrir los más de 900.000 nuevos empleos tecnológicos que serán necesarios en el corto plazo ${ }^{21}$. A nivel nacional, la demanda de profesionales está limitando la capacidad de evolucionar nuestros sectores productivos, algo que según la Encuesta Nacional de Innovación 2016 le ocurre a más del 20\% de las empresas españolas, incapaces de innovar por la falta de personal capacitado para ello22.

Pero este problema no es único en España o la Unión Europea, aunque nuestra burocracia lo acrecienta aún más. El crecimiento exponencial del número de empresas tecnológicas ha sido una constante durante más de una década, y países como Estados Unidos, Reino Unido o China, entre muchos otros, cubren su déficit de ingenieros y trabajadores con habilidades STEM ${ }^{23}$ con profesionales de todo el planeta, gracias a atractivas ofertas económicas que solo las grandes empresas tecnológicas son capaces de poner encima de la mesa y un marco regulador que permite una mayor captación de profesionales de altas capacidades.

Un país como España, con una elevadísima especialización turística y comprobada competitividad durante décadas para atraer enormes masas de visitantes, debería diseñar un plan para pivotar hacia el "turismo tecnológico" unido al talento, las startups y el nomadismo digital. Esta apuesta quizás no sea difícil en exceso si se eligen espacios altamente competitivos en términos de ecosistemas de innovación. Las ciudades medias con una muy alta calidad de vida, precios no muy elevados, excelentes comunicaciones y hábitats extraordinarios para residir (aprovechando los enormes stocks inmobiliarios existentes) deberían ser, junto a sus universidades y una economía digital en alza, una base muy interesante para crear un gran hub de referencia europeo y mundial.

Esto que en teoría suena fácil y atractivo en la práctica no lo es. La división de competencias entre el Estado, las comunidades autónomas, las corporaciones locales y los municipios fomenta un conjunto de actuaciones dispersas y faltas de la necesaria coordinación que en gran medida diluyen los esfuerzos. El talento queda pues a merced de las políticas universitarias (como el ICREA catalán) o la propia pericia de las grandes consultoras multinacionales, empresas nórdicas o anglosajonas (incentivadas por fenómenos como el Brexit) que vienen a captar informáticos y programadores españoles, con una buena imagen en el mercado internacional.

\footnotetext{
${ }^{21}$ Ver en: ec.europa.eu/commission/commissioners/2014-2019/ansip/blog/digital-skills-jobs-and-need-get-more-europeans-online en

${ }^{22}$ Datos públicos en ine.es, en la sección Ciencia y Tecnología: https://www.ine.es/prensa/eie_2016.pdf

${ }^{23}$ Las habilidades STEM (Science, Technology, Engineering, Math) hacen mención a los puestos de trabajo más relacionados con las nuevas tecnologías: científicos, tecnólogos, ingenieros y matemáticos.
} 
GRÁFICO 6. PREVISIÓN DE CRECIMIENTO DEL PIB ANUAL PARA 2035, CON Y SIN INCORPORACIÓN DE IA EN LA ECONOMÍA

Crecimiento base

Crecimiento con inversión constante en IA

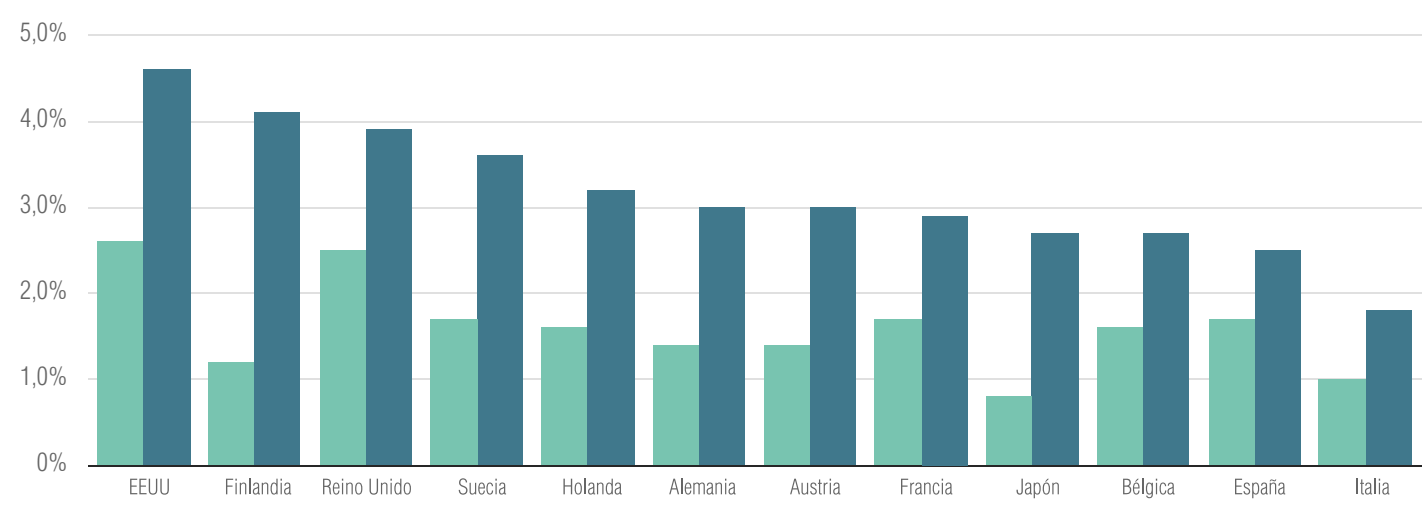

Fuente: Accenture y Frontier Economics

En Estados Unidos y en otros países líderes el talento internacional fluye mundialmente entre las corporaciones públicas (universidades, programas gubernamentales) y privadas (gigantes tecnológicos, startups...); mientras en España se generan compartimentos bastante estancos. España debe cambiar bastantes cosas de cara a construir espacios internacionales de referencia que sean auténticos ecosistemas capaces de consolidar empresas y captar el mejor talento mundial.

Es fácil de diagnosticar, por tanto, que aquellos países o regiones con escaso desarrollo de la economía digital y nula apuesta por la IA y el resto de "grandes tecnologías disruptoras” se convertirán en economías dependientes, con una pérdida sistemática de empleo en las industrias tradicionales, y la escasa generación de nuevos empleos digitales. Estadísticamente, algunas fuentes nos hablan de una ocasión que puede incrementar hasta un 50\% el valor del crecimiento anual en unos años gracias a la incorporación de estas tecnologías (Ver "Gráfico 6. Previsión de crecimiento del PIB anual para 2035, con y sin incorporación de IA en la economía" en la página 20). Para España significaría aumentar su previsión de crecimiento medio del PIB de un 1,7\% a un 2,5\% en las próximas dos décadas, aunque hay otros casos más extremos, como Japón, que pasaría del $0,8 \%$ a un $2,7 \%$.

Pero para ello, como se ha advertido antes, es necesario llegar a ser competitivo en el mercado de la IA y las "grandes disruptoras" y sin la identificación, desarrollo, atracción, retención y explotación de talento será prácticamente inviable. Aunque se trata de un tema verdaderamente complejo, sin un plan ambicioso y coordinado entre las universidades, empresas, emprendedores y el sector público será realmente difícil propiciar éxitos nacionales e internacionales relevantes. $Y$ con ello se requiere hacer una interesante reflexión sobre las actuaciones que debemos tomar.

Algunas instituciones públicas y privadas basan toda su actuación en programas sin 
seguimiento, o directamente shows para jóvenes sobre emprendimiento y economía digital. Lejos de estar resuelta la cuestión, con este tipo de actuaciones (quizá necesarias, pero verdaderamente parciales e insuficientes) llenamos páginas hablando de montar empresas, y hemos pasado de estigmatizar el fracaso a considerarlo un supremo fin, vendiendo la falsa idea de que es algo positivo, y no tanto las lecciones que aprendes por el camino, los puestos de trabajo que has generado, o la diversificación realizada y que puede ser el futuro de una nueva actividad.

También se requiere un mayor esfuerzo para afrontar con garantías la urgente hibridación de todas las disciplinas de conocimiento con la computación. La IA marcará de forma irreversible, como ya hemos dicho, el futuro de nuestra economía y nuestros empleos. Esto implica que, sin dilación, todas las materias educativas se integren con los conocimientos y herramientas computacionales si quieren explotar un enorme potencial de innovación y progreso. La medicina, la biología, la arquitectura, la economía, la educación, la agricultura... cualquier campo que pensemos puede tener desarrollos muy interesantes gracias a esta hibridación, que en muchos casos no se tratará de una mera opción, sino de un auténtico salvavidas.

Sin embargo, en demasiadas ocasiones la hibridación de áreas de estudio con la computación queda en meras propuestas formativas en las que se juntan dos compartimentos cerrados sin relación entre sí. Aún hoy puede resultar sorprendente que los títulos relacionados con la empresa, o la salud, o cualquier otra área puedan impartirse sin computación. Pero más sorprendente es, desde nuestro punto de vista, que una vez detectado el problema, no se pongan los mimbres necesarios para avanzar hacia modelos formativos completamente integrados, que trabajen con proyectos realistas, y que satisfagan las necesidades detectadas para garantizar empleos de calidad a nuestros estudiantes.

Este tema es verdaderamente preocupante, ya que pese a los esfuerzos realizados, Europa está seca de grandes empresas tecnológicas y de unicornios. Y no es por la dificultad de crear empresas digitales. Cada día surgen cientos en nuestro entorno. E problema está en la escalabilidad del negocio, y si el entorno en el que suscribimos estas empresas permite el desarrollo competitivo de nuestras startups. Pero quizás el problema sea más complejo de lo que pueden plantear las universidades o centros de formación superior, y requiera, por tanto, que con urgencia se introduzca en la educación primaria y secundaria un idioma más: el lenguaje computacional con el claro propósito de familiarizar a nuestros niños y jóvenes con este tipo de pensamiento. Esto hará más fácil que los médicos, abogados, biólogos, filólogos, arquitectos, físicos o economistas aprovechen el infinito potencial de la computación, la explotación de su big data, o las herramientas como machine learning o deep learning, y, por supuesto, que nuestros profesores universitarios hibriden la computación correctamente con las disciplinas convencionales.

En definitiva y como conclusión, maximizar un saldo neto positivo entre empleos destruidos y generados por el impacto de la IA y las "grandes disruptoras" será posible únicamente con políticas muy activas en educación, desarrollo y captación de talento, algo 
que deberá pasar por la hibridando de la computación con otras disciplinas y sectores. De esta forma se sembrará una sólida competitividad de un cierto largo recorrido.

\section{APLICABILIDAD A LA EMPRESA Y BENEFICIOS: UN CASO ESPECÍFICO Y ACTUAL, LOS CHATBOTS ${ }^{24}$}

Hay pocas dudas de que sectores clave como la sanidad, la educación, la banca o los sectores energéticos, liderados por organismos públicos o grandes empresas, acabarán más tarde o temprano de explotar todo el potencial de la IA que la legislación permita y el entorno mundial imponga. Pero lo realmente crucial en torno a la IA quizá sea la creación de una cultura digital receptiva que permita a las pequeñas y medianas empresas (pymes), a los sectores tradicionales y a la población en general abrazar su potencial.

Avances en el reconocimiento de imágenes son ya explotadas en multitud de sectores desde la conducción automática, pasando por la medicina, los controles de seguridad o la ropa hecha a medida. Se fijan ambiciosas metas a la hora de predecir y anticipar el comportamiento de los mercados y los gustos de los consumidores, incluso la capacidad de personalizar para cada individuo los productos y servicios. Otras empresas como Airbnb, Netflix o Amazon emplean el aprendizaje autónomo para segmentar audiencias y recomendar productos lo más adecuados posible a cada tipo de consumidor, generando un marketing cada vez más personalizado, que aprende sobre cada individuo de forma individualizada. Y tampoco podemos obviar el uso de la IA para la seguridad y detección de fraudes, o para la gestión de recursos energéticos, e incluso para gestionar logísticamente una fábrica.

Como vemos, existen numerosas aplicaciones más que interesantes de empleo de IA, ¿pero por donde empiezan las pymes? Un caso interesante para asimilar la cultura de la IA es el chatbot conversacional: un programa que basado en la IA y otros desarrollos informáticos es capaz de mantener una conversación o ejecutar acciones a demanda con una persona real25.

Aún en su infancia, están ya llamados a revolucionar la relación de las empresas con sus clientes y sus propios empleados. Su introducción puede ser un motor de asimilación de esta nueva cultura en torno a la IA y la economía digital. Forbes califica la Inteligencia Artificial Conversacional como la "Fase Final de la Revolución de la Información" y señala que ya es más efectiva a la hora de vender online, generar leads o incrementar la productividad en todas la facetas de la comunicación ${ }^{26}$. Sin duda, es un paso revolucionario en la forma en la que los usuarios se comunican e interactúan en el mundo digital.

24 Para este capítulo hemos recogido la información y experiencia de una startup española en esta materia: $\underline{1 \text { millionbot. }}$ $\underline{\mathrm{com}}$

${ }^{25}$ Ver, por ejemplo, un caso de aplicación en España de la IA de Google con tecnología española de 1millionbot.com referida al sector universitario en Pedreño (2018).

${ }^{26}$ Reddy, S. (2018, 18 de agosto). Conversational Artificial Intelligence - The Final Phase Of The Information Revolution. Forbes. Recuperada en: forbes.com/sites/forbestechcouncil/2018/08/17/conversational-artificial-intelligence-the-finalphase-of-the-information-revolution/ 
Hasta hace nada considerábamos y seguimos considerando una página web o una app algo extremadamente valioso, que han servido para expandir el comercio online o para el desarrollo de plataformas de servicios tan extendidas como Airbnb, Uber, Cabify, o la compraventa de criptomonedas.

Pero en realidad, las analíticas de los smartphones, pese al diseño responsive que casi todas las empresas han adoptado, nos han develado que las apps o las páginas web son propuestas muy "burdas" para comunicarnos con los usuarios: aunque se hayan desplegado las técnicas más sofisticadas de Design Thinking y Customer Experience, asistimos a altísimos porcentajes de rebote, bajísima capacidad de generar usuarios recurrentes, nula capacidad para identificar necesidades y tendencias, o problemas subyacentes en la tecnología empleada ${ }^{27}$. Para los millennials las webs o algunas apps son rudimentarias y aburridas. Les hacen perder tiempo.

Frente a esto, las propuestas que Google (Home) o Amazon (Echo) quieren colocarnos en casa evidencian que lo lógico y cómodo es que un usuario pregunte o pida algo con su lenguaje natural y la tecnología se lo facilite. El teléfono móvil está pidiendo a gritos una comunicación con el usuario de este tipo. Una experta como Nuria Oliver no duda incluso en plantear su desaparición ${ }^{28}$. Y de nuevo, las empresas que no adapten sus sistemas a esta nueva cultura pueden quedar muy rezagada,s e incluso descolgadas del mercado.

Un chatbot puede canalizar toda la comunicación interna y externa de una empresa. Con un tamaño superior a 50 empleados la comunicación interna de la empresa requiere de estructuras costosas y poco eficaces para canalizar la información interna. Un chatbot, como ocurre con casi todas las tecnologías de inteligencia artificial, es una revolución en toda regla. Su volumen de datos generados permitiría identificar hasta el estado emocional positivo o negativo global de una empresa de 200.000 empleados y de una sucursal de menos de 50. Amén de la identificación de problemas, permite asimismo recoger los feedbacks de clientes, agilización de pedidos, dar una respuesta en cualquier momento, etc.

Sin embargo, a día de hoy la comunicación externa a través de la tecnología chatbot es una revolución de una entidad todavía difícil de evaluar, pero muy fácil de intuir, y que tendrá una implicación importantísima en comercio online, en la asistencia telefónica y call centers, en la captación de leads... Un "vendedor" amable, capaz de dar un trato personalizado, que trabaja 24 horas los 7 días de la semana, que ejecuta peticiones de los clientes -una reserva, un pedido, una orden de compra- y que llega a atender una queja. Los "first adopters" ya tienen resultados concluyentes: los chatbots mejoran no

\footnotetext{
27 Con la experiencia de los años se ha asistido a empresas que, después de hacer aparentemente sus deberes, dejan fuera de su mercado a elevados porcentajes de usuarios por cuestiones como no hacer pruebas de las Apps en diferentes plataformas; no comprobar que las plataformas de pago sean hábiles en distintos sistemas operativos; no realizar suficientes pruebas de estrés...

28 Entrevista concedida al diario Información, el 13 de junio de 2017. Recuperada en: diarioinformacion.com/alicante/2017/06/13/nuria-oliver-movil-desaparecera-futuro/1905456.html
} 
sólo los costes, sino que además ya empiezan a vislumbrar los efectos positivos en la relación con los clientes, especialmente en las tasas de conversión y ventas.

\section{CONCLUSIONES}

Más que hacer una recapitulación de lo que hemos señalado anteriormente, como incidir en la necesidad de un país como España, y el conjunto de Europa, asuman la relevancia del impacto de la IA en términos económicos y sociales y que derive en una muy ambiciosa apuesta, quizás sea más importante dedicar unos minutos a resaltar los riesgos económicos de la pasividad, siendo conscientes de que otros especialistas resaltarán otros riesgos éticos más relacionados con sus disciplinas (ética, derecho, tecnología). Entre dichos riesgos, destacamos:

a) Pérdida de competitividad notable durante los próximos años derivada de la insuficiente o tardía proactividad y liderazgo gubernamental: Que los gobiernos españoles no asuman la entidad de los impactos, la importancia y ambición de las apuestas y estrategias internacionales en torno a la IA, nos convertirá en una economía dependiente, con escaso grado de digitalización respecto a terceros. Infravalorar la velocidad y la entidad del cambio y sus consecuencias por parte de nuestro país -o Europa- contrasta con la aparición de algunos líderes políticos que se han percatado de lo estratégico y decisivo que resulta una gran apuesta por la IA, con planes muy ambiciosos para el desarrollo de las llamadas tecnologías disruptoras y el desarrollo de sectores de futuro.

b) Disrupción negativa en sectores clave de la economía española: Los sectores clave de la economía española no han abordado hasta la fecha, en tiempo y forma, su transformación digital, lo que comporta importantes efectos negativos que se volverán a repetir si no nos ponemos al día. La crisis económica es un claro síntoma de este modelo: mientras las economías digitalizadas supieron recuperar su ritmo de crecimiento en pocos años, nuestros sectores, tradicionales y poco innovadores, aún sufren algunas consecuencias, y será muy difícil que vuelvan a recuperar su capacidad de creación de empleo.

c) Incentivar el impacto laboral negativo: Infravalorar la convulsión de las tecnologías disruptoras y la digitalización frente a la apuesta por los sectores tradicionales generará un crecimiento más lento de nuestra economía, que en definitiva debilita la creación de nuevos empleos potenciales de alta cualificación, con mayor proyección, más productivos, y con rentas más elevadas.

d) Devaluar la captación y generación de talento: No tomar en consideración el papel crucial del talento, de la educación (pensamiento computacional), la hibridación universitaria y el déficit de recursos humanos en torno a la computación y la IA, es sinónimo de debilidad en torno al sector de la economía digital en general.

e) No facilitar la explotación de grandes volúmenes de datos: El Big Data es el alimento de la Inteligencia Artificial. Si no se provee de datos al conjunto de empresas, su desa- 
rrollo será limitado para incluso nuestros sectores más representativos, como la sanidad, el turismo y la banca.

f) Primar regulación sobre educación: La necesidad de crear una cultura tecnológica de base es imprescindible sobre una sociedad "tutelada" con regulaciones absurdas que fagocitan el desarrollo de la economía digital en España o en Europa, mientras que otros países incrementan su liderazgo y, por extensión, nuestra dependencia económica respecto a ellos. Necesitamos una población formada, educada en las restricciones y riesgos ligados a la tecnología digital (privacidad, ciberseguridad, vulnerabilidad, ética). No primar lo suficientemente la educación en favor de la regulación tiene perversas consecuencias para el desarrollo de la economía digital.

Para terminar, convendría recordar al historiador Yuval Noah Harari en su obra Sapiens (2014): "La ciencia moderna es una tradición única de conocimiento, por cuanto admite abiertamente ignorancia colectiva en relación con las cuestiones más importantes [...]. La buena disposición de la ciencia a admitir ignorancia ha hecho que la ciencia moderna sea más dinámica, adaptable e inquisitiva que cualquier otra tradición previa del conocimiento".

Quizás, y debido a la convulsión que la actual tecnología producirá en nuestros sistemas actuales económicos, estemos en condiciones de reinventar la propia economía. Conceptos como producción, precios, consumo, utilidad, empleo, dinero, distribución, escasez y renta deban ser revisados. La Inteligencia Artificial dotará a la ciencia económica de nuevas herramientas y mecanismos que romperán ideas y teorías preconcebidas para convertirla, por suerte, en una disciplina bastante creativa.

\section{BIBLIOGRAFÍA}

Arntz, Melanie; Gregory, Terry and Zierahn, Ulrich (2016). The risk of automation for jobs in OECD countries: a comparative analysis, OECD social, employment and migration working papers, n.189. Paris: OECD

Chien, Steve and Wagstaff, Kiri L. (2017). Robotic space exploration agents. Science Robotics, vol. 2, n. 7.

DOI: http://dx.doi.org/10.1126/scirobotics.aan4831

Coulson, Robert N., Folse, L. Joseph, and Loh, Douglas K. (1987). Artificial intelligence and natural resource management. Science, vol. 237, n. 4812, pp. 262-267.

DOl: http://dx.doi.org/10.1126/science.237.4812.262

Di Minin, Enrico, Fink, Christoph, Tenkanen, Henriki, and Hiippala, Tuomo (2018). Machine learning for tracking illegal wildlife trade on social media. Nature ecology \& evolution, 
V. 2, n. 3, pp. 406-407.

DOI: https://doi.org/10.1038/s41559-018-0466-x

Ducrot, Raphaelle, Le Page, Christophe., Bommel, Pierre and Kuper, Marcel (2004). Articulating land and water dynamics with urbanization: an attempt to model natural resources management at the urban edge. Computers, Environment and Urban Systems, vol. 28 , n. 1-2, pp. 85-106

DOI: https://doi.org/10.1016/S0198-9715(02)00066-2

Godown, Mandaline E., and Peterson, Andrew T. (2000). Preliminary distributional analysis of US endangered bird species. Biodiversity \& Conservation, vol. 9, n. 9, pp. 13131322

DOI: https://doi.org/10.1023/A:1008924322405

Hamet, Pavel and Tremblay, Johanne (2017). Artificial intelligence in medicine. Metabolism, vol. 69, pp. 36-40.

DOI: https://doi.org/10.1016/j.metabol.2017.01.011

Harari, Yuval Noah (2014). Sapiens. De animales a dioses: Una breve historia de la humanidad. Debate: Madrid

Nijkamp, Peter, Vindigni, Gabriella and Nunes, Paulo A. (2008). Economic valuation of biodiversity: A comparative study. Ecological economics, vol. 67, n. 2, pp. 217-231

DOI: https://doi.org/10.1016/j.ecolecon.2008.03.003

Nilsson, Nils J. (1984). Artificial intelligence, employment, and income. Al magazine, vol. 5, n. 2, pp. 5-14

DOI: https://doi.org/10.1609/aimag.v5i2.433

Frey, Carl Benedikt and Osborne, Michael A. (2017). The future of employment: how susceptible are jobs to computerisation?. Technological forecasting and social change, vol. 114, N. C, pp. 254-280

DOI: https://doi.org/10.1016/j.techfore.2016.08.019

Patel, Vimla L., Shortliffe, Edward H., Stefanelli, Mario, Szolovits, Peter, Berthold, Michael R., Bellazzi, Riccardo and Abu-Hanna, Ameen (2009). The coming of age of artificial intelligence in medicine. Artificial intelligence in medicine, vol. 46, n. 1, pp. 5-17

DOI: https://doi.org/10.1016/j.artmed.2008.07.017

Pedreño, Andrés (2818). "Por qué los chatbot universitarios son importantes. El caso del chatbot de la UMU”. Pendiente de publicación. Acceso público en:

https://docs.google.com/document/d/1EAWyUaTdgYAAczIFigFOWvWKUtOxQhJheU3wYadSw8

Perez-Ayucar, Miguel; Almeida, Miguel; Ashman, Mike; Costa, Marc; García, J.; M.T. Hoofs, Raymond; Kueppers, Michael; Merritt, Donald; Marín-Yaselí de la Parra, Julia; Nespoli, 
Federico.; Sanchez Suárez, Eduardo; Chien, Steve and Rabideau, Gregg (2016). Science Data Volume management for the Rosetta spacecraft. In International Conference On Space Operations (SpaceOps 2016), Daejeon, Korea, May 2016

DOI: https://doi.org/10.2514/6.2016-2489

Peterson, Andrew. T. (2003). Projected climate change effects on Rocky Mountain and Great Plains birds: generalities of biodiversity consequences. Global Change Biology, vol. 9, n. 5, pp. 647-655

DOI: https://doi.org/10.1046/j.1365-2486.2003.00616.x

Peterson, Andrew. T., Ortega-Huerta, Miguel A., Bartley, Jeremy, Sánchez-Cordero, Víctor., Soberón, Jorge, Buddemeier, Robert H., and Stockwell, David R.B. (2002). Future projections for Mexican faunas under global climate change scenarios. Nature, vol. 416, n. 6881, pp. 626

DOI: https://doi.org/10.1038/416626a

Quaglini, Silvana, Barahona, Pedro and Andressen, Steen (Eds.). Artificial Intelligence in Medicine, Proceedings of 8th Conference on Artificial Intelligence in Medicine in Europe, AIME 2001, Cascais, Portugal, Springer, July 2001

Russell, Stuart J., and Norvig, Peter (2016). Artificial intelligence: a modern approach. Pearson Education Limited: Malaysia

Spangler, Scott, Wilkins, Angela D., Bachman, Benjamin J., Nagarajan, Meena, Dayaram, Tajhal, Haas, Peter, and Stanoi, Ioana (2014). Automated hypothesis generation based on mining scientific literature. In Proceedings of the 20th ACM SIGKDD international conference on Knowledge discovery and data mining, pp. 1877-1886. ACM

DOI: https://doi.org/10.1145/2623330.2623667

Tripathi, Shivam, Srinivas, V. V., and Nanjundiah, Ravi S. (2006). Downscaling of precipitation for climate change scenarios: a support vector machine approach. Journal of hydrology, vol. 330, n. 3-4, pp. 621-640

DOl: https://doi.org/10.1016/j.jhydrol.2006.04.030

Troesch, Martina, Chien, Steve and Ferguson, Eric (2017). Using Automated Scheduling to Assess Coverage for Europa Clipper and JUpiter ICy moons Explorer, In International Workshop on Planning and Scheduling for Space (IWPSS 2017), Pittsburgh, PA, June 2017

Varis, Olli and Kuikka, Sakari (1999). Learning Bayesian decision analysis by doing: lessons from environmental and natural resources management. Ecological Modelling, vol. 119, n. 2-3, pp. 177-195

DOI: https://doi.org/10.1016/S0304-3800(99)00061-7 


\section{ii. Aspectos legales de la Inteligencia Artificial y el Big Data}

Plaza Penadés, Javier*

* Catedrático de Derecho Civil de la Universitat de València

\section{CUESTIONES BÁSICAS DEL DERECHO EN MATERIA DEL BIG DATA Y LA INTELIGENCIA ARTIFICIAL}

El desarrollo reciente de la llamada sociedad de la información y del conocimiento, dentro de la llamada cuarta revolución industrial, ha generado una moderna economía, basada en el dato y en el algoritmo, que son la base del Big Data, la Inteligencia Artificial y la aparición de drones y robots (boots) humanizados o no.

El Derecho debe de adaptarse a esas nuevas realidades y dar una respuesta adecuada con base en tres criterios:

- Respetar los derechos fundamentales de la persona, ya que toda tecnología debe de desarrollarse teniendo en cuenta su impacto y el respeto de los derechos fundamentales de la persona.

- $\quad$ La adecuada protección jurídica de todas estas nuevas realidades: Big Data; algoritmos; aplicaciones, productos o servicios basados en la Inteligencia Artificial; boots o drones. Para ello siempre hay tres posibilidades básicas:

- Primera: aplicar las instituciones jurídicas a las nuevas realidades o, en todo caso, realizar leves adaptaciones.

- Segunda: partir de una institución jurídica conocida, pero con una adaptación tan singular a esa nueva realidad que realmente supone la creación de una nueva institución. Ese ha sido el caso del programa de ordenador o del derecho sui generis sobre base de datos.

- Tercera: crear un nuevo derecho específico.

- $\quad$ Y, por último, favorecer y promover el desarrollo económico y tecnológico garantizando una adecuada protección de las personas que invierten dinero y tiempo en estas nuevas realidades. 
Además, la Inteligencia Artificial y el Big Data son transversales y afectan a todos los sectores económicos: agrario, turístico, medioambiental, de transporte terrestre y, muy especialmente, de la medicina, tanto en el ámbito de la prevención como en el del tratamiento. De ahí la oportunidad y conveniencia de conocer, cuanto menos, la situación jurídica actual y las perspectivas de desarrollo de la misma.

\section{PRINCIPIOS RECTORES PARA EL BIG DATA Y LA INTELIGENCIA ARTIFICIAL}

A pesar de que el Big Data y la Inteligencia Artificial son tendencias lo suficientemente amplias en sí mismas y que además están en continua evolución, resulta conveniente identificar un conjunto de elementos compartidos entre ambas materias que pueden dar lugar a la definición de diversos principios rectores. Dichos principios deben ser tomados como pilares transversales sobre los que debería pivotar el régimen jurídico específico del Big Data y de la Inteligencia Artificial.

Los principios rectores deben de partir del respeto a estos principios rectores:

- Los derechos fundamentales de una persona deben siempre de prevalecer sobre los derechos de cualquier elemento basado en la tecnología. Es decir, la implementación de cualquier tecnología debe tener en consideración el respeto a los derechos fundamentales de la persona, especialmente los que conciernen a su libre desarrollo de la personalidad, el respeto a sus libertades básicas y el respeto a todos sus derechos fundamentales, como el honor, la intimidad personal y familiar, o el derecho de protección de datos de carácter personal. En ese sentido, una tecnología respetuosa con los derechos fundamentales desde sus inicios y diseñada para garantizar el respeto continuo a los mismos, es una tecnología de mayor calidad y permite un desarrollo mucho más fiable desde el punto de vista de la seguridad jurídica.

- Las tecnologías deben corregir y evitar cualquier sesgo o implementación que suponga discriminación, especialmente de origen racional, o que sea irrespetuosa con diversos colectivos de personas y sensibilidades, como las que tienen que ver con la raza o la orientación sexual de las personas. Además, hay características privadas de los individuos que deben quedar en la esfera privada y que no deben de influir en las predicciones y análisis de la IA, dado que repercutiría en sesgos de valoración y hechos discriminatorios.

- Asimismo, las tecnologías deben ser profundamente respetuosas con el desarrollo y los derechos de las personas menores.

- Las tecnologías deben estar orientadas al respeto a la dignidad de la persona, y a los derechos a la vida y a la integridad física, favoreciendo la protección integral de la salud de las personas y permitiendo una mayor integración y utilización entre las personas que padecen algún tipo de discapacidad física o psíquica. 
- $\quad$ Debe de haber una especial aplicación del principio de proporcionalidad en el uso de la tecnología cuando para la consecución de un fin lícito, como la protección de los menores o la prevención y persecución del delito, esté justificada alguna intromisión a la intimidad de la persona o a los derechos básicos del menor o de personas con capacidad de obra modificada, siempre que se realice de forma proporcionada, tratando de ser lo menos invasiva posible y lo más respetuosa con la persona.

\section{UN MARCO NORMATIVO PARA EL BIG DATA Y LA INTELIGENCIA ARTIFICIAL}

\subsection{MARCO NORMATIVO ACTUAL}

El marco jurídico aplicable al Big Data y la Inteligencia Artificial se compone por un conjunto de normas que lo regulan, aunque ninguna lo hace de forma específica para este tipo de tratamiento de datos masivos.

Actualmente, en el ordenamiento jurídico, la normativa que tiene una mayor incidencia en la aplicación del Big Data es la relativa a la protección de datos contenida en la nueva Ley orgánica de protección de datos de carácter personal (LOPD) y el Reglamento General de Protección de Datos, Reglamento 2016/679 de 27 de abril (RGPD); si bien ambas normas no tienen como cometido regular los aspectos personales y patrimoniales del Big Data.

Además de la normativa de protección de datos, será de aplicación indirecta y tangencial al Big Data la normativa de propiedad intelectual, el derecho sui generis sobre bases de datos y la normativa sobre protección de secretos comerciales (Directiva 2016/943), la LSSI y del CE, la Ley de Transparencia y otras normas especiales conexas.

Con todo, no existe ninguna ley que regule de forma específica, especial y sistematizada todas las cuestiones relativas a la titularidad, protección, utilización, derechos y límites de los datos masivos.

\subsection{ASPECTOS JURÍDICOS DEL BIG DATA}

En materia de Big Data debemos distinguir dos ámbitos: aquel en el que se usan datos personales de personas físicas identificadas o identificables y aquel en que los datos no son personales (por ejemplo, datos de valores medioambientales que se utilizan para prevenir riesgos de salud en las Smart Cities). Los datos personales gozan de una protección y de una legislación específica, mientras que los datos no personales no estarían sometidos a dicha legislación de LOPD y rgpd

Pero también es posible que datos personales en origen sean luego anonimizados, no permitiendo identificar a personas físicas concretas en modo alguno. Para ello, es necesario obtener el consentimiento inicial e informado de la persona para su tratamiento, 
pero su uso posterior en una gran base de datos ya no requeriría de consentimiento.

\subsubsection{Protección de datos personales y Big Data}

Con independencia de la titularidad pública o privada de los productos y servicios derivados del Big Data, se debe tener en consideración que los datos personales están sometidos a una normativa muy protectora de los derechos fundamentales de las personas.

En concreto datos de carácter personal son los relativos a cualquier información numérica, alfabética, gráfica, fotográfica, acústica o de cualquier relativa o concerniente a personas físicas identificadas o identificables. Pero, además, si esos datos afectan a la intimidad, a las creencias, a la orientación social o a la salud de la persona o pueden suponer discriminación, son datos especialmente protegidos.

Por ello, los datos personales deben ser tratados y utilizados de conformidad con lo previsto en la Ley o a través de un consentimiento implícito -nunca presunto-, informado y transparente, ya que la persona, en atención a su derecho fundamental de protección de datos, tiene derecho a saber en todo momento cuál es el uso y destino de dichos datos personales.

Además, datos sensibles o especialmente protegidos requieren de consentimiento expreso y escrito. Es fundamental, para garantizar el adecuado desarrollo de la industria del Big Data y la legalidad de los productos y servicios obtenidos con esta técnica, que el principio de transparencia y de calidad de la información se respete en todo momento, y que, si es necesario ampliar o modificar los fines y usos inicialmente previstos, se informe de forma transparente a las personas físicas cuyos datos se han solicitado de

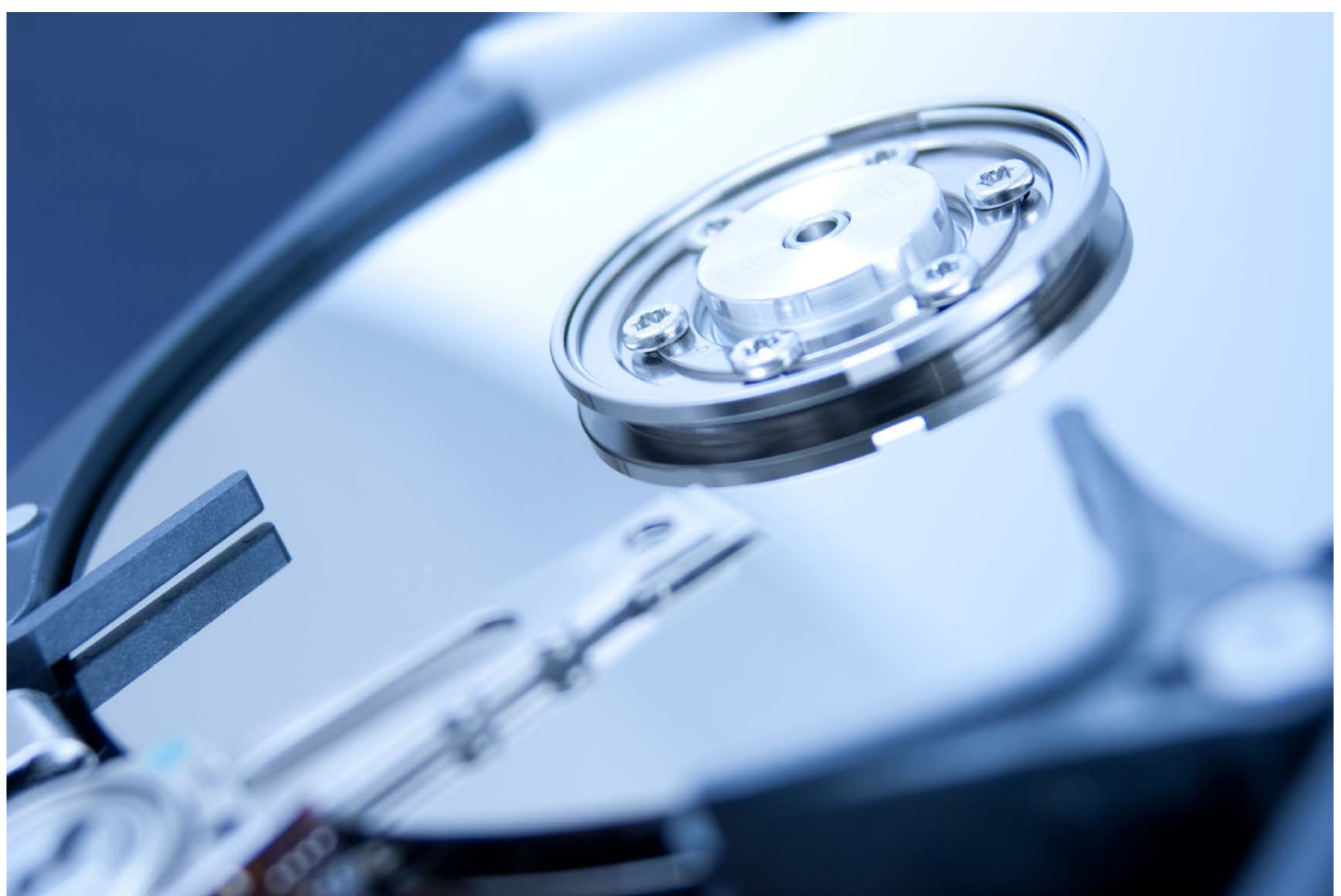


manera expresa.

Igualmente, la persona debe ser informada de los procesos de disociación de la información personal de los datos, de cómo va a quedar preservada su identidad, de si existe riego o posibilidad de reversión o de si el proceso de anonimización es totalmente seguro. $\mathrm{O}$, dicho con otras palabras, debe advertirse si el proceso de anonimización resulta reversible, pues no se estaría ante un proceso de anonimización, sino ante un proceso de seudonimización.

En los procesos de seudonimización de los datos existe la posibilidad de revertir la operación para volver a conocer la identidad de los afectados. Estos procesos no pueden evitar que se apliquen las normas sobre protección de datos personales porque, aunque no pueda identificarse el afectado al que se le ha asignado un seudónimo, la reversión en la operación no evita que los afectados pierdan la cualidad de identificables.

Pero la información sobre estos procesos no debe de impedir ni minimizar el principio de transparencia y de calidad de la información, especialmente cuando se amplía o varía el uso de datos personales, ya que es la base para el correcto funcionamiento de este sector económico.

Además, el contexto del Big Data ha desarrollado dos nuevos derechos en materia de protección de datos de carácter personal: el derecho al olvido, que debe de permitir que informaciones irrelevantes, que ya no son actuales y que inciden negativamente en la dignidad de la persona y en su honor e intimidad, puedan ser suprimidas de la red y que ya no sea posible encontrar dicha información a través de Google y otras herramientas de búsqueda similares. Ese derecho está reconocido a nivel legal en el artículo 17 del Reglamento 2016/679, de 27 de abril, general de protección de datos (RGPD).

Por otro lado, y en un nivel de protección superior, estarían aquellos supuestos en los que recaban datos masivos de una persona concreta sin su consentimiento, mediante inducción de conclusiones y predicciones respecto a la información obtenida del análisis de los datos masivos. Si estas conclusiones afectan a valoraciones de personas respecto a decisiones que tengan trascendencia jurídica, existe un grave peligro de vulnerarse sus derechos. El mero hecho de cruzar datos de manera automatizada para obtener perfiles de personas, grupos o colectivos ya puede resultar tendencioso en sí mismos, pero requiere en todo caso de conocimiento previo y también posterior, para ver si el resultado alcanzado es real o actual.

Para ello, se contempla el denominado derecho de "oposición a la elaboración de perfiles o profiling" del artículo 21 RGPD. Este derecho está ideado para evitar que no se evalúe o juzgue a las personas exclusivamente por tratamientos de datos que no han sido ofrecidos directamente por el afectado provocándoles perjuicios.

El $\underline{\text { RGPD }}$ permite estas decisiones tomadas por tratamientos automatizados siempre y cuando el interesado haya dado su consentimiento explícito y permitiendo al interesado impugnar esas valoraciones. En la práctica esta impugnación de valoraciones resulta 
muy poco eficiente por la dificultad de la prueba y por la dificultad de encauzar estas iniciativas individuales por parte de un ciudadano medio. Se trata de un derecho personalísimo que sólo puede ser ejercido por el afectado titular del mismo.

Sin embargo, en el momento en el que cualquiera puede ser afectado por un tratamiento masivo y puede verse perfilado o clasificado en un colectivo que pueda verse perjudicado, quizá sería conveniente extender a este ámbito el ejercicio de acciones colectivas. Puede parecer una paradoja el carácter personalísimo del derecho de la personalidad del afectado con la posibilidad de que se pueda ejercitar por otra persona o representante, pero si repercute en beneficio del protegido tampoco debiera observarse como un sistema incongruente. Hay que ser conscientes de que en el momento en el que son grandes empresas las que van a manejar el Big Data y lo van a procesar con sistemas de IA que han sido diseñados, en principio, para obtener productos que beneficien a los afectados, tiene sentido que consideramos a estos afectados como consumidores o usuarios.

\title{
Puede parecer una paradoja el carácter personalísimo del derecho de la personalidad del afectado con la posibilidad de que se pueda ejercitar por otra persona o representante, pero si repercute en beneficio del protegido tampoco debiera observarse como un sistema incongruente.
}

No es la primera vez que se extiende el concepto técnico o propio de consumidor o

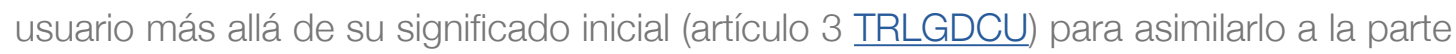
débil de la relación jurídica. Si se toma este concepto de consumidor o usuario en sentido amplio, podría también facilitarse la entrada de las acciones colectivas para la defensa de los intereses difusos y colectivos. Es decir, en aquellos casos en los que pueda considerarse que estas actividades implican valoraciones o predicciones que afectan a colectivos que se han perfilado mediante el procesamiento de datos, podría legitimarse a asociaciones de usuarios (nacionales y europeas), al ministerio fiscal y a la propia Administración para impugnar y emprender acciones legales.

\author{
Es necesario definir un concepto de \\ "patrimonio personal de datos personales" \\ que permita su cuantificación y comercialización por los particulares \\ en la medida en que \\ los datos personales son cada vez más valiosos \\ en el tráfico patrimonial
}

Asimismo, casos como el de los usos de los datos personales que han hecho redes sociales al margen de los usuarios reflejan como el marco normativo actual es insufi- 
ciente para conocer el alcance real de las infracciones y permitir las reclamaciones individuales de responsabilidad civil por el daño moral o por el uso patrimonial de los datos propios, por lo que es necesario definir un concepto de "patrimonio personal de datos personales" que permita su cuantificación y comercialización por los particulares en la medida en que los datos personales son cada vez más valiosos en el tráfico patrimonial.

- 3.2.2 Big Data sobre datos económicos, científicos o sociales no personales. Concepto y alcance de la llamada "minería de textos y datos"

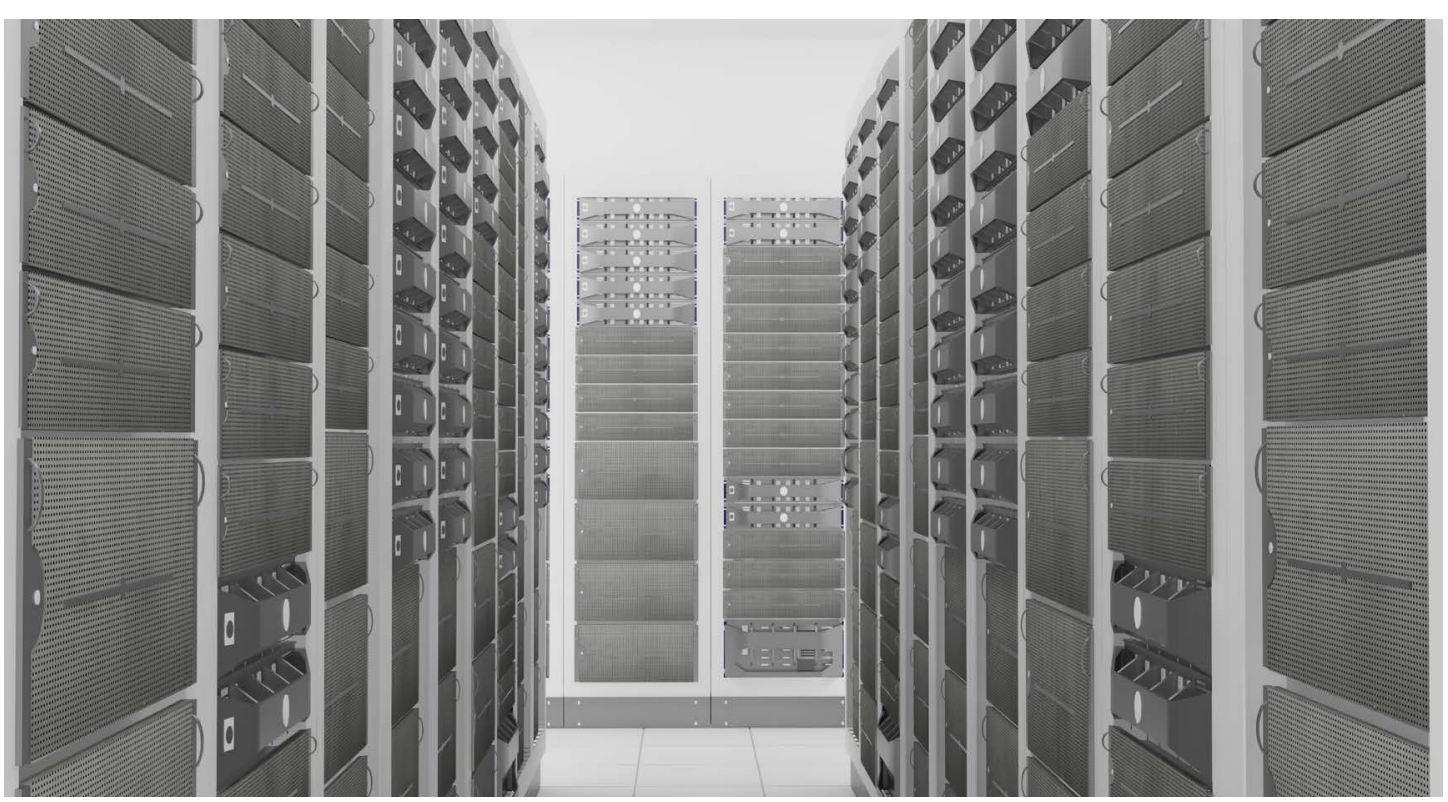

Y respecto de los datos no personales, estos pueden ser obtenidos por empresas privadas y particulares o por la Administración Pública y organismos del sector público, otorgándole al "titular de la base de datos masivos", el derecho a utilizar y explotar onerosa o gratuitamente, en todo o en parte, dicha base de datos masivos, y delimitando durante el período de explotación las utilizaciones lícitas por terceras personas (fair uses).

Con ello, en una economía de los datos dinámica y con un correcto funcionamiento legal, la delimitación de la titularidad y de sus usos lícitos permite y garantiza una protección objetiva y eficaz del flujo de datos, dando una cobertura legal ante la fuga, el tráfico, la pérdida, el robo de información, el espionaje industrial y la competencia desleal. La protección, por tanto, de dicho flujo de datos abarcaría desde la propia generación, al acceso a las fuentes de datos, así como al tráfico de información.

Respecto a la protección del dato, ¿cómo proteger lo datos valiosos que se tienen? La solución que se ha dado desde la propiedad intelectual, en el Derecho europeo, es a través de una protección específica consistente en un derecho sui generis de base de datos, estableciendo así un derecho de exclusiva sobre el acceso a esa base de datos, su utilización y las condiciones de extracción de los mismos, pero siempre que la elaboración de dicha base de datos conlleve un importante esfuerzo en tiempo o dinero (artículo 133 y ss $\underline{\text { TRLPI)}}$. 
Es decir, las bases de datos que por la selección o la disposición de su contenido constituyan una creación intelectual de su autor estarán protegidas, como tal creación, por los derechos de autor, pero además también gozan de protección aquellas que suponen un importante esfuerzo en tiempo y en dinero, por lo que este derecho sui generis de bases de datos debe de adaptarse a lo que podemos llamar "base de datos masivos".

Además, respecto a la protección en el flujo de datos, entrarían en juego unas condiciones contractuales para facilitar el cambio de proveedor de servicios. Dado que la portabilidad de los datos y el cambio de proveedor de servicios de datos son interdependientes, se podría contemplar la elaboración de unas cláusulas contractuales tipo que exigieran al prestador de servicios incluir la portabilidad de los datos de un cliente.

Recientemente, la Propuesta de Directiva de Derechos de autor en el mercado digital (y que en breve estará aprobada), ha desarrollado el concepto de "minería de textos" y de "minería de datos" (text and data mining), ya que por "minería de textos y datos" se entiende cualquier técnica analítica automatizada para analizar textos y datos en formato digital a fin de generar información sobre pautas, tendencias o correlaciones.

El fin de la Directiva es que dicha minería la puedan realizar universidades e institutos dedicados a la investigación libremente, respecto de obras publicadas, como base de datos sui generis, como una excepción a los derechos de propiedad intelectual, de tal suerte que desaparezca la inseguridad jurídica, estableciendo una excepción obligatoria respecto del derecho de reproducción, así como del derecho de prohibir la extracción de una base de datos, con el deseo de que no se pueda impedir, ni tan siquiera con licencia de uso, para el caso de "organismos de investigación", esto es, "una universidad, un instituto de investigación o cualquier otra organización cuyo principal objetivo sea realizar investigaciones científicas o realizar investigaciones científicas y prestar servicios educativos".

En definitiva, la forma de proteger los datos son a través del secreto -del know-how-, del que hablaré a continuación al hilo de la protección de los algoritmos- o publicándolo. Y, en su caso, como base de datos sui generis, podrán limitar por licencia de uso la minería de datos y textos, si bien, la propuesta de la Directiva de derechos de autor en el mercado digital prevé una excepción a esas limitaciones en favor de organismos de investigación.

Ha nacido un nuevo paradigma en donde la industrialización y comercialización de los datos es el principal valor financiero para las compañías al tiempo que es necesario jurídicamente garantizar su desarrollo desde la base del respeto a los derechos fundamentales, desde la protección del patrimonio basado en el dato personal y desde el punto de vista de optimizar los resultados directos e indirectos derivados del Big Data, y garantizar asimismo su adecuada protección legal, ya que una regulación legal fuerte y equilibrada debe ser la base para el desarrollo de este nuevo sector estratégico de la economía del dato. 


\subsection{ASPECTOS JURÍDICOS DE LA INTELIGENCIA ARTIFICIAL SUSCEPTIBLES DE SER REGULADOS}

— 3.3.1 Titularidad y protección del algoritmo a través de la nueva regulación del secreto comercial o de alguna institución de propiedad intelectual o industrial

El algoritmo en principio es inapropiable y no se puede pretender detentar sobre él ningún monopolio legal, en el sentido de que no se puede impedir que cualquier tercero llegue lícitamente a formular y utilizar un mismo algoritmo, siempre que lo obtenga de modo lícito por sus propios medios e investigaciones, por lo que las normas de secreto industrial (know-how) y competencia leal son esenciales.

En ese sentido, en materia de know-how, aunque no hay ley española en el momento de redactar este capítulo, sí que disponemos de una Directiva. Es la Directiva (UE) 2016/943 del Parlamento Europeo y del Consejo, de 8 de junio de 2016, relativa a la protección de los conocimientos técnicos y la información empresarial no divulgados (secretos comerciales) contra su obtención, utilización y revelación ilícitas, que debía de haberse incorporado a nuestro Derecho el pasado 9 de junio de este año, 2018, pero no ha sido así.

Cierto es que en el Congreso de los Diputados se está tramitando el Proyecto de Ley de Secretos empresariales, pero también es verdad que su tramitación termina de iniciarse, por lo que seguro que aún tardará algunos meses en ser aprobada; eso siempre que no haya un anticipo de elecciones, en cuyo caso decaería dicha tramitación y la demora en la incorporación a nuestro Derecho sería todavía mayor.

Sin embargo, y pese a que no está incorporada todavía a nuestro Derecho, conviene recordar que el "principio de primacía" del derecho de la Unión Europea obliga, señala el Tribunal Constitucional, a aplicar las Directivas tal y como han sido interpretadas por el Tribunal de Justicia de la Unión Europea, "con preferencia sobre el derecho interno incompatible" (STC 232/2015, de 5 de noviembre, FJ 6º ECLI:ES:TC:2015:232), y en ese sentido, ya podemos hacer una interpretación legal del concepto de secreto industrial o comercial (know-how), junto con otros aspectos legales; más allá de que también sabemos que el proyecto de Ley española recoge todo lo dicho en la Directiva de la Unión Europea.

Así, en estos momentos, podemos señalar tres aspectos muy importantes de la citada Directiva y de su incidencia actual en el Derecho español:

1) El primero es que su aplicación no es solo al ámbito estricto de la empresa, ya que no queda reducido al secreto empresarial, sino que se extiende a todos los conocimientos técnicos y la información empresarial no divulgados (secretos comerciales). De ahí que la expresión secreto comercial o know-how nos parezca más ajustada, desde un punto de vista estrictamente técnico jurídico, y es más indicativo de lo que es el objeto de protección, ya que la expresión "secreto empresarial" puede llevar al error de pensar que se refiere únicamente a los secretos 
que surgen en la empresa y no a las ideas y secretos surgidos fuera de la empresa, pero que tienen una marcado valor y proyección comercial, y que también quedarían incluidos en la aplicación lógica de la Directiva, aunque sea por interpretación extensiva.

En ese sentido, la Directiva señala: "Las empresas, así como los organismos de investigación de carácter no comercial, invierten en la obtención, desarrollo y aplicación de conocimientos técnicos (know-how) e información, que son la moneda de cambio de la economía del conocimiento y proporcionan una ventaja competitiva. Esta inversión en la generación y aplicación de capital intelectual es un factor determinante para su competitividad y su rendimiento asociado a la innovación en el mercado y, por tanto, para la rentabilidad de sus inversiones, que constituye la motivación subyacente a la investigación y el desarrollo en las empresas.

Las compañías utilizan diferentes medios para hacer suyos los resultados de sus actividades asociadas a la innovación cuando optar por la apertura no permite la plena explotación de sus inversiones en investigación e innovación. Uno de esos medios es recurrir a los derechos de "intellectual property", como las patentes, los derechos sobre dibujos y modelos y los derechos de autor. Otro medio para apropiarse de los resultados de la innovación consiste en proteger el acceso a los conocimientos que son valiosos para la entidad y que no son ampliamente conocidos, y explotarlos. Esos conocimientos técnicos y esa información empresarial de gran valor, que no se han divulgado y que se quieren mantener confidenciales, se conocen con el nombre de "secretos comerciales".

2) El segundo es que al menos tenemos un concepto legal de secreto comercial o know-how, que es muy valioso, desde un punto de vista estrictamente jurídico, ya que tiene una enorme trascendencia práctica. En concreto, el concepto de "secreto comercial" de conformidad con el artículo 2 apartado 1 de la Directiva, se proyecta sobre toda idea o información que reúna los siguientes tres requisitos:

- Que sea secreta en el sentido de no ser, en su conjunto o en la configuración y reunión precisas de sus componentes, generalmente conocida por las personas pertenecientes a los círculos en que normalmente se utilice el tipo de información en cuestión, ni fácilmente accesible para estas;

- Que tenga un valor comercial por su carácter secreto; y además,

- Que haya sido objeto de medidas razonables, en las circunstancias del caso, para mantenerla secreta, tomadas por la persona que legítimamente ejerza su control;

Se trata de un concepto muy valioso, ya que en primer lugar exige tratar al secreto con medidas adecuadas de protección, tanto físicas o técnicas, para evitar su conocimiento, incluso dentro de la empresa o del ámbito de investigación en el que se está desarrollando para que no sea accesible a cualquier persona, como legales, y, en ese sentido, se 
van a generalizar los contratos de confidencialidad y los contratos en los que se indica los usos y las titularidades derivadas de esas ideas o conocimientos secretos.

Pero lo más importante, para ser considerado secreto, es que la idea o conocimiento de que se trate sea "en su conjunto o en la configuración y reunión de sus componentes, generalmente desconocida por las personas pertenecientes a los círculos en que normalmente se utilice el tipo de información en cuestión".

Por otra parte, nada impide tampoco que un algoritmo pueda ser informatizado y utilizado como "programa de ordenador", con la protección que como software le dispone la Ley de Propiedad Intelectual.

Respecto de la patente, la Ley Española de Patentes establece que no se considerarán invenciones los planes, reglas y métodos para el ejercicio de actividades intelectuales, para juegos o para actividades económico-comerciales, así como los programas de ordenador. Se entiende, por tanto, que ello constituye una exclusión de los algoritmos como objeto patentable en sí mismo, algoritmos que participan además de la naturaleza de meros descubrimientos lo que dificulta su patentabilidad, sin perjuicio de que algún novedoso producto o procedimiento para desarrollar un producto pueda valerse o implementar un algoritmo. Es el caso, por ejemplo, del aspirador "roomba", cuyo funcionamiento se basa en un algoritmo que cubre toda la superficie de un piso o vivienda o dependencia que se desea limpiar.

Por ello, en la práctica, los registros de patentes de la mayoría de los países admiten el registro de algoritmos cuando éstos se presentan juntamente con otros productos o procedimientos que son sobre los que se proyecta la patente.

Por tanto, más allá de pequeños ajustes en la legislación de propiedad intelectual, la empresa española debe tener los suficientes mecanismos de información pública como para proteger de forma adecuada y utilizar como ventaja competitiva los algoritmos que tienen valor comercial o que suponen un beneficio para la sociedad, bien a través de las normas de secreto comercial o know-how, bien buscando su incorporación y utilización en productos de propiedad intelectual o industrial.

3.3.2 Protección de las obras intelectuales resultado de Inteligencia Artificial. El encaje actual en el derecho de autor y en la futura Directiva comunitaria

Las aplicaciones de Inteligencia Artificial necesitan de un análisis específico para determinar su naturaleza jurídica o protección a través de la propiedad intelectual. Por ejemplo, la máquina que gana al campeón de ajedrez es en realidad un software que combina y utiliza todas las variantes que han ido introduciendo gradualmente en la misma, a una velocidad cada ver mayor. Sin embargo, limitada a esa funcionalidad, jurídicamente es un software.

Otro caso es el de los programas de traducción inteligente de idiomas. Son, en realidad, 
un software que combina minería de datos de traducciones publicadas en textos oficiales y no oficiales en internet, y también son cada vez mayores. De hecho, al incorporar una aplicación o funcionalidad de lectura y correcta pronunciación, son capaces de llegar a la máquina que es capaz de hacer la función de intérprete, pero la máquina, ya tiene un fabricante, que fabrica la máquina con el software incorporado.

Por tanto, habrá que analizar cada caso en concreto y ver que protección jurídica se ofrece: si la de un programa de ordenador o si la de una base de datos. El problema radica en que en la legislación del derecho de autor las obras en que la interacción humana es mínima o inexistente pueden tratarse de dos formas: puede denegarse la protección del derecho de autor respecto de las obras generadas por un dispositivo computacional o puede atribuirse la autoría de esas obras al titular de la máquina o dispositivo, si bien aquí ya se combinan aspectos de propiedad intelectual (titularidad de software o base de datos) con propiedad material (titular fabricante del producto o soporte).

La tendencia a corto plazo va a ser a que el titular de la máquina que haya incorporado software, minería de datos y demás aplicaciones, ya sean de titularidad suya o ya sea mediante adquisición de licencia de uso, lo fabrique y comercialice como producto. Será, por tanto, titular del "producto", que integra hardware y software de IA, como en el caso ya visto del titular de la máquina que limpia el polvo del forma autónoma.

Por tanto, más allá de pequeños ajustes en la legislación de propiedad intelectual e industrial, la empresa española debe tener los suficientes mecanismos de información pública como para proteger de forma adecuada todas las creaciones e invenciones que forman parte de la llamada Inteligencia Artificial.

\section{LA POSIBILIDAD DE CONSIDERAR A LOS ROBOTS COMO ENTIDAD PROPIA CON DERECHOS PROPIOS}

La Inteligencia Artificial se está manifestando principalmente como una evolución más de la llamada sociedad de la información y del conocimiento, del desarrollo del Internet de las cosas, del Big Data y de la economía de los datos, todo ello fruto de la Inteligencia Humana.

Obviamente la IA representa una enorme oportunidad de desarrollo económico y social para todos los sectores económicos y productivos, desde el agrario y agroalimentario, pasando por la industria del transporte (con la idea del vehículo teledirigido de forma segura), hasta la redefinición de las propias tecnologías de la información y de la comunicación, que están siempre en continua evolución.

Como toda invención o novedad, está rodeada de una cierta desconfianza o temor. De ahí que un desarrollo ético y jurídico adecuado de la Inteligencia Artificial deba de servir, más allá de garantizar la debida seguridad jurídica, para generar confianza en dichas herramientas, productos o servicios, que deben de tener como fin el progreso de la 
humanidad.

Cierto es que, desde un punto de vista de la seguridad, no hay que temer a las máquinas y a estas nuevas aplicaciones y servicios de IA, sino a algunos hombres que las pueden utilizar indebidamente, lo que plantea un verdadero desafío a la seguridad, tanto física como tecnológica, especialmente de las llamadas infraestructuras críticas, como centrales nucleares, presas y satélites, entre otras. Y obviamente el Derecho y los cuerpos dedicados a la seguridad y a la defensa no subestiman ni deben subestimar estas nuevas amenazas.

Como bien es sabido, la palabra inteligencia viene del latín intellegere, término compuesto de inter "entre» y legere «leer, escoger», y, por tanto, hace referencia a esa habilidad humana de analizar todas las posibilidades y escoger la que se cree, en ese momento y según las circunstancias, que es más adecuada. $Y$ ese proceso puede ser ahora auxiliado por la IA.

Pues bien, toda Inteligencia Artificial, como realidad tecnológica, debe tener en cuenta que los derechos fundamentales de la persona y la dignidad del ser humano están por encima de cualquier tecnología y que su diseño inicial y su previsible desarrollo debe de respetar siempre y en todo momento dichos derechos y principios. Esta prevalencia de la dignidad humana sobre la máquina como base del desarrollo jurídico de la IA conecta y concreta las famosas leyes que, de forma jerárquica, Asimov desarrolló en sus obras de ciencia-ficción.

La primera Ley, y prevalente sobre las demás, es que la máquina y la Inteligencia Artificial no pueden causar daño al ser humano, ni tan siquiera por omisión. La segunda es que las máquinas y la Inteligencia Artificial deben cumplir siempre las órdenes dadas por los seres humanos, salvo que sean contrarias o entren en conflicto con la primera Ley. $Y$ la última de las leyes es el reconocimiento de una cierta ontología a las máquinas con Inteligencia Artificial (lo que la Unión Europea ha llamado "personas electrónicas"), para asegurar su existencia y evitar su autodestrucción, ya que un robot o sistema de IA debe proteger su propia existencia, siempre que ello respete y sea compatible con las dos primeras leyes.

Sobre esa base se debe de asentar los principios tecnológicos y jurídicos de la Inteligencia Artificial que, tanto a efectos de titularidad como de responsabilidad, deben de recaer en personas físicas o jurídicas, pero no en las llamadas "personas electrónicas".

En definitiva, se abre una nueva era, la de las máquinas autónomas e independientes, similares, pero nunca idénticas ni superiores a los seres humanos, junto con el desarrollo real y efectivo de la Inteligencia Artificial, donde el progreso y la I.H. (Inteligencia Humana) se van a desarrollar todavía más y donde las oportunidades de empleo deberán de buscarse precisamente en saber desarrollar esta tecnología y saber utilizarla convenientemente. 


\section{RESPONSABILIDAD DE DECISIONES ROBOTIZADAS / AUTOMATIZADAS.}

Relacionado con lo anterior, se aborda la necesidad de resolver la responsabilidad por los daños causados por un dispositivo basado en IA. En principio, cuando el daño ha sido causado por cualquier máquina o herramienta será una cuestión técnica determinar si el responsable civil ha sido el propietario, el operario o el fabricante o si, como se sugiere por algunos, no habría responsabilidad del fabricante o titular del robot o de las aplicaciones de Inteligencia Artificial causante de daños, sino que la responsabilidad recaería sobre la "persona electrónica" o la aplicación de IA.

Por tanto, con el actual marco jurídico, los robots o las aplicaciones de IA no pueden en sí mismos ser considerados responsables de los actos $u$ omisiones que causan daño a terceros. Además, las normas vigentes en materia de responsabilidad abarcan aquellos casos en los que es posible remontarse hasta un agente humano concreto a quien imputar la acción u omisión del robot o aplicación. Esa es la base de la llamada responsabilidad del fabricante por los productos defectuosos (responsabilidad que no entra en los mecanismos de culpa).

Por ello, y en mi opinión, en materia de responsabilidad, desde un punto de vista jurídico, debe de mantenerse de momento y a un largo plazo, el criterio de que es responsable la persona física o jurídica titular del robot o de la aplicación de Inteligencia Artificial causante de los daños, consecuencia de la primacía del ser humano y su dignidad sobre las llamadas personas electrónicas, y además, consecuencia de que en toda acción de indemnización de daños y perjuicios hay un componente resarcitorio que requiere de un patrimonio (conjunto de bienes o derechos) sobre el que ejercer dicho resarcimiento, por lo que para poder exigir responsabilidad a una máquina o aplicación de Inteligencia Artificial sería necesario que, además de ser causante autónomo y "culpable o responsable" del daño, fuese titular de un patrimonio con el que la víctima del daño pudiera resarcirse, algo que resulta difícil de imaginar, ya que está todavía muy lejano.

Todo ello al margen de que para delimitar la responsabilidad por daños, es imprescindible que exista una prueba de daño o nexo causal entre el comportamiento dañino o perjudicial entre la máquina o robot y el daño sufrido por la otra parte; y sin perjuicio de los criterios de concurrencia de culpas o de fuerza mayor. Por tanto, los modelos de aseguramiento y de responsabilidad civil deben de prever, en principio, que será el titular o fabricante del robot o de la aplicación de Inteligencia Artificial el responsable, a salvo de la concurrencia de culpa de la víctima o de fuerza mayor. 


\section{CONCLUSIONES}

- Los necesarios procesos de alfabetización digital básica deben de incluir sin demora los aspectos legales esenciales que lo usuarios debe de conocer de Big Data e Inteligencia Artificial, así como los medios actuales de los que se dispone para ejercitar dichos derechos y garantizar su cumplimiento.

- $\quad$ En ese proceso de información y difusión resulta necesario que todas las empresas y todos los centros de investigación en materia de Big Data e Inteligencia Artificial puedan conocer como proteger mejor todas las aplicaciones, productos y servicios basados en BD e IA (por marca, diseños, patentes, modelos de utilidad, protección de software y bases de datos, know-how...) y como deben utilizarse con respeto a los derechos fundamentales y al marco normativo vigente.

- $\quad$ Es más, en materia de Big Data, y aprovechando la incorporación de la Directiva sobre Derechos de autor en el mercado digital (actualmente como Propuesta, pero ya en su fase final de tramitación), resultaría conveniente el desarrollo de una normativa ad hoc que regule el uso de las "bases de datos masivos", personales y no personales, tanto de titularidad pública como privada, y el desarrollo de las políticas de transparencia pública, con la puesta a disposición de un elevadísimo número de datos en abierto, que combinado con instrumentos de open access, junto con los preceptos de la citada propuesta de Directiva, permitiría el desarrollo de productos, servicios y aplicaciones de gran utilidad social y cuyos resultados deben quedar protegidos.

- En materia de Inteligencia Artificial, tanto la titularidad como la responsabilidad, deben de recaer en el fabricante de dicho producto, que puede ser una máquina, autónoma o teledirigida, con o sin apariencia humana, con hardware y software lícito (ya sea porque es propio o porque se ha adquirido y se está utilizando dentro de la licencias de uso). Pero no parece conveniente que se reconozca a las máquina personalidad jurídica; esto es, capacidad jurídica y de obrar para ser titular de derechos y derecho, por lo que no pueden tener responsabilidad propia, más allá de que no tengan patrimonio o capacidad patrimonial para hacer frente a dicha responsabilidad.

- $\quad$ Por tanto, en caso de productos de Inteligencia Artificial, la titularidad y la responsabilidad deben de recaer sobre el lícito fabricante. Lo que es necesario es prever y clarificar, incluso desde un punto de vista normativo, los conflictos que puedan surgir entre titulares de los derechos de propiedad intelectual e industrial y los fabricantes de productos de IA cuando se hayan utilizado recursos de propiedad intelectual ajenos. 


\section{BIBLIOGRAFÍA}

Castells, Marina (2017). La subjetividad "ciborg", aproximaciones Inteligencia Artificial. Colección Tecnología y derecho, pp. 231-257

Camacho, Sandra (2017). Derecho e inteligencia artificial desde el diseño, aproximaciones Inteligencia Artificial. Colección Tecnología y derecho, pp.23-72

Coulson, Robert N., Folse, L. Joseph y Loh, Daniel K. (1987). Artificial intelligence and natural resource management. Science, vol. 237, n. 4812, pp. 262-267

DOI: https://www.doi.org/10.1126/science.237.4812.262

Hamet, Pavel and Tremblay, Johanne (2017). Artificial intelligence in medicine. Metabolism, vol. 69, pp. 36-40.

DOI: https://www.doi.org/10.1016/j.metabol.2017.01.011

Mateo Borge, Iván (2017). La robótica y la inteligencia artificial en la prestación de servicios jurídicos e Inteligencia Artificial, Colección Tecnología y derecho, pp. 123-150

Navas Navarro, Susana (2017). Derecho e inteligencia artificial desde el diseño, aproximaciones Inteligencia Artificial, Colección Tecnología y derecho, pp. 23-72

Nijkamp, Peter, Vindigni, Gabriella and Nunes, Paulo. A. (2008). Economic valuation of biodiversity: A comparative study. Ecological economics, vol. 67, n. 2, pp. 217-231

DOl: https://doi.org/10.1016/j.ecolecon.2008.03.003

Vázquez de Castro, Eduardo (2018). Titularidad y responsabilidad en la economía del dato. Revista Aranzadi de Derecho y Nuevas Tecnologías, n.46, pp. 74-91 


\section{iii. Empresas basadas en Big Data e Inteligencia Artificial}

\section{DOS MÉTODOS DE APRENDIZAJE}

Siendo el objetivo de este ebook el impulso de estas dos tecnologías disruptoras como pilares de pequeños y medianos proyectos empresariales, este tercer capítulo recoge la apuesta de dos startups de la Comunitat Valenciana insertas en el sector de las Tecnologías de la Información y la Comunicación y especializadas en el uso como método de trabajo de la Inteligencia Artificial. Son Santa Barbara Smart Health, ubicada en el Parc Científic de la Universitat de València, y Nouss Intelligence, instalada en el Parque Científico de la Universidad de Alicante.

Aunque basadas ambas en IA, es decir, en la creación de dispositivos o algoritmos que omiten o reemplazan al ser humano emulando sus funciones cognitivas, las dos compañías se fundamentan en dos tipos distintos de ciencia de datos, en dos métodos diversos de aprendizaje.

Por un lado, Santa Barbara Smart Health aplica la IA para llevar a cabo procesos de Machine-Learning; esto es, analizar datos para intentar extraer conocimiento de los mismos y traducirlo en algoritmos que permitan la predicción futura. Por tanto, permite reconocer patrones en un conjunto masivo de datos.

Y, por otro lado, Nouss Intelligence lleva a cabo el llamado Deep Learning o aprendizaje profundo. Sus motores tratan de imitar al cerebro humano, elevando el aprendizaje a un nivel más detallado. Las máquinas aprenden gracias a la orientación del hombre, que en cierto modo les enseña cómo deben actuar y qué procesos seguir. En este sentido, lo que aporta el Deep Learning es la posibilidad de generar independencia, de aprender por su cuenta, encontrar significados y realizar asociaciones. 
Año de creación: 2016

Misión: Esta startup trabaja para mejorar la calidad de vida de los pacientes renales mediante la innovación y desarrollo de herramientas software que dan soporte al diagnóstico médico y asisten a los profesionales médicos en la toma de decisiones. En última instancia, su meta es hacer efectiva la llamada medicina de precisión.

Equipo de profesionales: 6 científicos de Inteligencia Artificial, 1 arquitecto software, 4 desarrolladores de software y 2 asesores médicos

Ubicación: Parc Científic de la Universitat de València

El conocimiento médico crece en estos momentos a tal velocidad que hace que sea casi imposible para un ser humano estar al día de la literatura médica más actualizada (publicaciones científicas, guías clínicas... ) De ahí, que la Inteligencia Artificial despierte un gran interés teniendo en cuenta sus posibilidades para involucrarse, aprender y desarrollar patrones en situaciones donde se requiere un gran acervo de conocimientos médicos, procesamiento ágil de los datos y la toma efectiva de decisiones.

En este contexto, la compañía alemana Fresenius Medical Care, especialista en desarrollo de productos y servicios destinados al tratamiento de pacientes con insuficiencia renal, apostó por usar las nuevas tecnologías disruptivas basadas en IA para transferir conocimiento y cultura médica al "point-of-care", esto es, a sus profesionales médicos. En última instancia, su principal meta era mejorar el tratamiento de los enfermos renales.

Tomada la decisión, en un primer momento la división europea de la empresa decidió implementar a nivel interno un departamento de desarrollo. De este modo, configuró en 2009 en Italia el departamento Care Value Advanced Analytics. Lo conformó un equipo de 7 doctores en IA que debían trabajar concretamente sobre datos clínicos estructurados sobre historias clínicas de pacientes almacenadas en el sistema clínico de NephroCare (EuCliD). Debían diseñar herramientas software que aprendieran a partir de datos, compusieran patrones y dieran soporte a los médicos en la toma de decisiones.

Los resultados generaron tal satisfacción que a partir del año 2016 Fresenius vió la necesidad de crear otro equipo para trabajar en problemas de datos no estructurados en los que se hace necesaria la interpretación de texto clínico (historias clínicas y prospectos médicos). Este equipo cuenta con 7 profesionales a tiempo completo y 4 a tiempo parcial, entre los cuales se cuenta con 6 doctores en IA, dos estudiantes de Medicina en el último año, y 4 Ingenieros Informáticos. Nació entonces en el Parc Científic de la Universitat de València la startup tecnológica: Santa Barbara Smart Health. 
Carlo Barbieri es director de Care Value Advanced Analytics en Fresenius y ejerce su cargo en las oficinas de la compañía en Italia. Fue él quien se puso al frente del proyecto, que recibió el impulso definitivo después de fracasar la externacionalización con grandes compañías tecnológicas, como IBM.

"El primer ámbito donde hemos aplicado la IA era en el manejo de la anemia en pacientes con fallo renal. Queríamos analizar cómo afecta a los pacientes de diálisis. Al no tener conocimiento interno de Inteligencia Artificial en el seno de la empresa, buscamos a las personas que en aquel momento estuvieran trabajando en este tema en universidades europeas. La sorpresa fue localizar en la Escola Tècnica Superior d'Enginyeria (ETSE) de la Universitat de València al grupo de investigación IDAL (Intelligent Data Analysis Laboratory). En aquellos momentos eran de los pocos especialistas que analizaban el manejo de la anemia en pacientes de diálisis", explica el responsable. "Fue entonces cuando establecimos un convenio de trabajo con ellos".

El IDAL trabaja en técnicas basadas en Inteligencia Computacional y ha obtenido como resultado algoritmos que ya han sido aplicados con éxito en el campo de la Medicina y de la Farmacia, como cardiología, urología, radiología y optimización de dosis de fármacos, entre otros.

La ciudad de Valencia atrajo a la compañía tanto por los desarrollos de IDAL como por la cercanía geográfica con su sede italiana de Cremona. "Unos de los principales beneficios de la colaboración público-privada ha sido el soporte de la Universitat de València para encontrar rápidamente el talento que necesitábamos. Pudimos consultar al profesorado experto en IA quienes eran los mejores estudiantes en esta área de conocimiento y ofrecerles trabajar con nosotros", explica Carlo Barbieri.

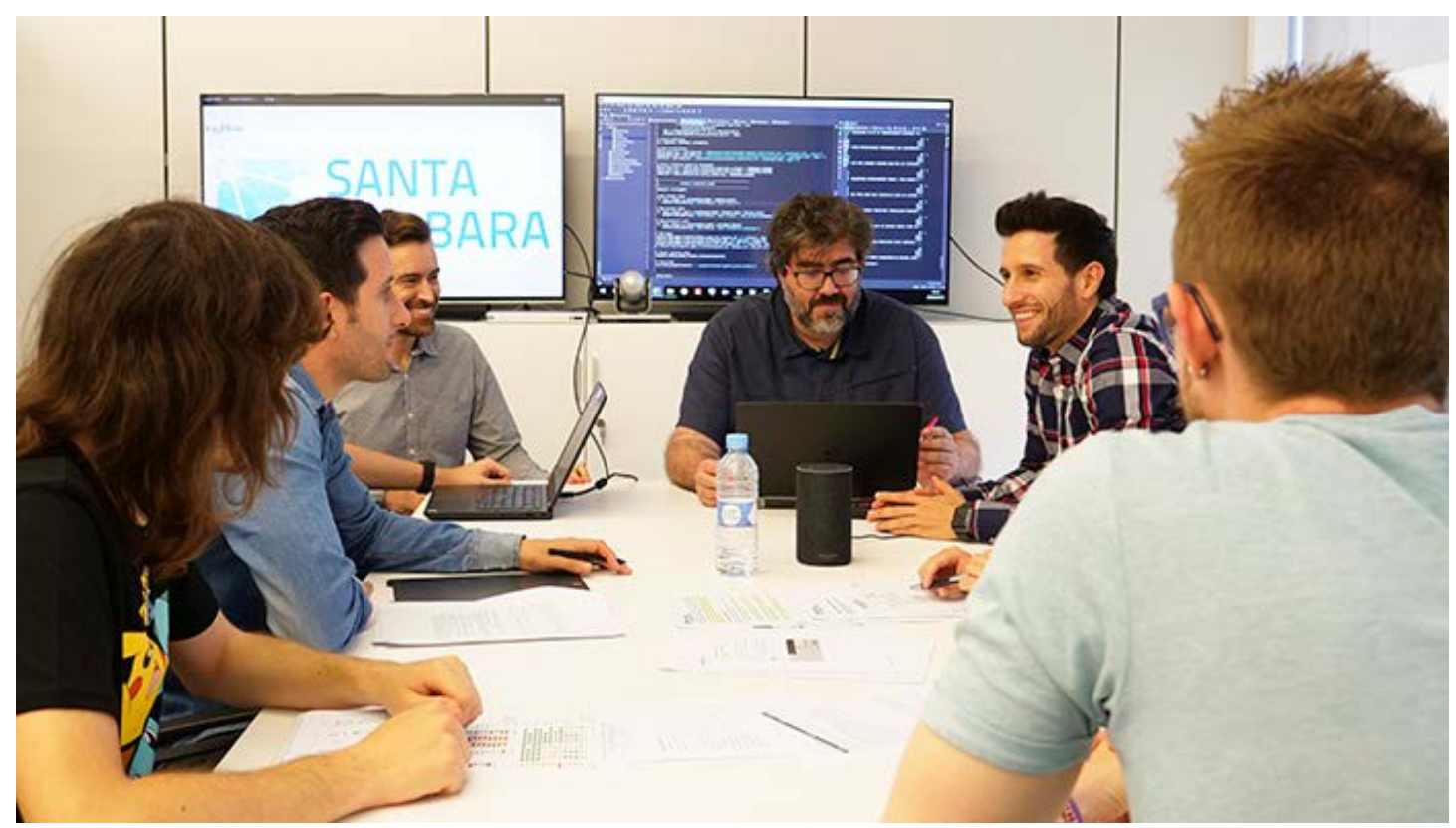




\title{
"Uno de los principales beneficios de la colaboración público-privada ha sido el soporte de la Universitat para encontrar rápidamente el talento que necesitábamos"
}

\begin{abstract}
"Además, la Universitat tiene, muy cerca de la ETSE, el Parc Científic (PCUV), un lugar ideal para trabajar. Aunque hoy en día los equipos pueden trabajar desde cualquier parte del mundo, al final debemos tener presente la utilidad de las reuniones personales y el contacto humano. En el PCUV nos ofrecieron una amplia oficina, tenemos alojados nuestros servidores en su centro de datos, y contamos con una serie de servicios que nos permiten trabajar en equipo de forma eficiente", añade Barbieri. Entre ellos, valora "el networking con empresas que trabajan en campos como la informática y la genética, con las que tenemos posibilidad de colaborar".
\end{abstract}

El tercer motivo que apunta como causa para ubicar su centro de desarrollo en Valencia es "el atractivo de la ciudad". "Pensamos que profesiones como la de científico en IA es un perfil muy demandado al que debes atender para evitar el "turn over". ¿Cómo? Dándole atractivos tanto para los empleados que son de aquí y los de fuera, pues la calidad de vida de esta ciudad es muy buena".

Fue entonces cuando se concretó una colaboración entre la Universitat y la empresa para hacer más efectivo los testeos de los modelos teóricos de la Universitat de València en ensayos clínicos de la red de clínicas del grupo Fresenius Medical Care. Crearon en 2011 en el Parc Científic de la Universitat de València un departamento de desarrollo, al que bautizaron primeramente Nephrocare E-Services.

\section{EL VALOR AÑADIDO}

Fresenius subraya como nota diferencial de sus desarrollos en IA el hecho de tener detrás el soporte de una compañía médica tradicional, donde aplicar los modelos previsionales de riesgo que sugieren una acción o alertan de un problema.

El funcionamiento clave de la empresa es el llamado Natural Language Processing (NLP), es decir, extraer automáticamente información médica de manera estructurada a partir de textos clínicos. En concreto, a partir de esta información se alimenta un cerebro artificial (IA) que la trata, en este caso, con modelos bayesianos y probabilísticos.

En 2016 el pequeño Departamento de Fresenius derivó en una compañía emergente. Se constituyó Santa Barbara Smart Health. Según su responsable, de nuevo Carlo Barbieri, el cambio obedece a una mejora de la logística: "Las empresas grandes tienen muchas ventajas, pero como desventaja, en una empresa grande todos los procesos y reglas son más costosos. Aunque todos los desarrollos que realizamos aquí deben ser aprobados por Fresenius para ser aplicados a nuestros dispositivos médicos, es cierto que la independencia como empresa hace que seamos más ágiles en la fase de desarrollo". 


\section{NUEVOS PERFILES Y METODOLOGÍAS}

La empresa cuenta con dos perfiles profesionales principales.

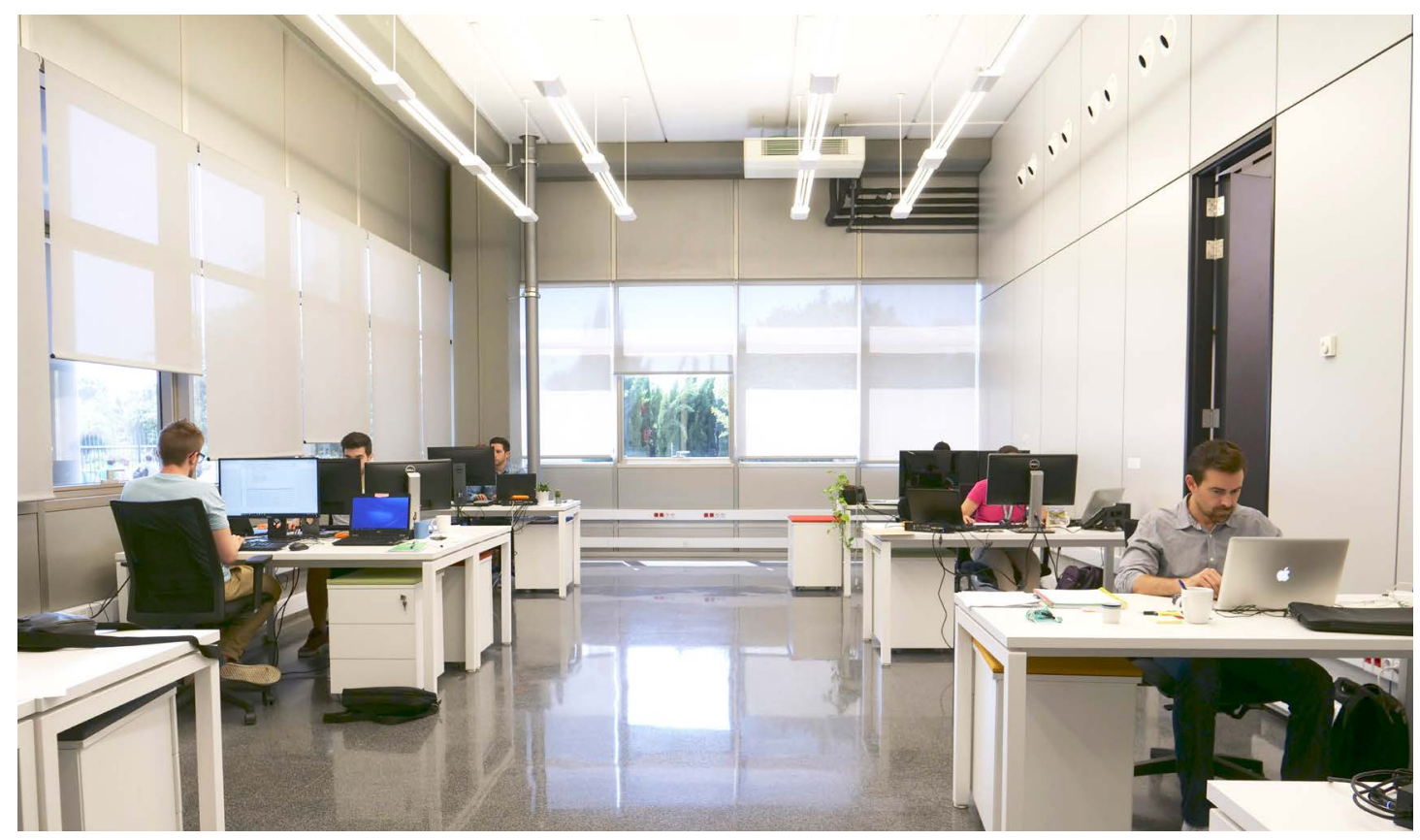

a) Expertos en Inteligencia Artificial (IA), que disponen de un doctorado en Computer Science con especialización en el área de Machine Learning. A partir de la información dispersa en guías clínicas, papers y el estado del arte, construyen modelos matemáticos que pueden recoger hasta un centenar de variables diferentes. De forma automática con IA, utilizando modelos NLP, archivan toda esa información disponible en una base de datos relacional.

b) Desarrolladores de software y arquitectura de bases de datos, quienes crean las herramientas estándar para poner los modelos de IA a disposición del usuario final. Este perfil profesional trabaja para que la app final utilice los menos recursos posibles del servidor y, por tanto, sea lo más eficiente y rápida posible. Dependiendo de cómo construyan las consultas a la engine, las respuestas pueden tardar de microsegundos a segundos.

c) Graduados en Medicina que aportan a los técnicos conocimiento técnico para los desarrollos.

\section{METODOLOGÍA SCRUM}

El trabajo de los diferentes equipos se organiza por objetivos que deben cumplirse semanalmente o cada dos semanas. Martín Navarro es el responsable de aplicar la metodología Scrum a la empresa: "La manera estándar de desarrollar un producto o servicio implica unos seis meses recogiendo requerimientos, luego se desarrolla y cuando acabas, lo hecho no sirve; esto es, cuando te enfrentas al problema real, ha cambiado el paradigma para resolverlo. Por ello, nosotros no esperamos a tener toda la información 
necesaria para realizar desarrollos. Empezamos realizando prototipos, aprendes mientras estás trabajando y los vas actualizando". En este sentido, debe tenerse presente que el desarrollo de software es bastante cambiante, por lo que es muy difícil planificar acciones a largo plazo."

\section{"El desarrollo de software es bastante cambiante, por lo que es muy difícil planificar acciones a largo plazo"}

Scrum significa «melé» en rugby y lo que esta metodología de trabajo busca es que todo el equipo conjunto se encargue de realizar la planificación de las tareas semanales. Contamos con un "scrum master", que es el que dirige el debate, y en este caso además es el propietario del producto, Carlo Barbieri. "Él nos indica las prioridades y los desarrollos que deben ejecutarse. Estas tareas se trasladan a un "back-log" o pizarra y se marca el "sprint" para realizarlo. Habitualmente nos marcamos dos semanas de tiempo para tenerlas hechas, y si vemos que hay tareas urgentes, el plazo es de una semana", explica Navarro.

"El lunes es el día en que anotamos las tareas en el "back-log" y marcamos el "sprint" calculando los puntos de historia, la complejidad que nos va a suponer y, por tanto, el esfuerzo. Activamos el "sprint" y a partir de ahí, todos los días nos reunimos 10 o 15 minutos para ver el progreso de la semana. En la reunión decimos que hemos hecho el día anterior, el día de hoy y si detectamos problemas para completar objetivos", continua Martín. "La idea también es que seamos un equipo, a pesar de la especialización, y cualquiera de nosotros pueda ayudar en todas las tareas. Especialmente habrá que dirigir esfuerzos a adelantar una tarea que va retrasada. Cualquier miembro puede entrar y completar esa tarea. Este es nuestro trabajo diario hasta el viernes, día en que la reunión es más intensa, pues cerramos el "sprint" y vemos qué objetivos están completados y cuáles no. En los casos negativos, buscamos cuál ha sido la causa, por ejemplo, optimismo a la hora de calcular el esfuerzo".

Una vez los productos están desarrollados, es decir, cuentan con el core de la IA, es el momento de construir productos digitales que serán aplicados por los médicos de Fresenius. Para ello, elaboran una api que puede aplicarse en cualquier software. Esta api permite a los usuarios conectarse a la base de datos generada. Conectará la parte inteligente que gestiona el conocimiento generado (la engine) con un sistema con el que el médico podrá interactuar y mejorar su capacidad de diagnóstico y tratamiento.

"Nosotros estamos más centrados en el servidor, que es el que realiza los cálculos. Para mostrar los resultados, desarrollamos un software muy práctico para que se pueda testear, pero no tenemos equipo de desarrollo web, que es el que diseñaría la aplicación con la que accede al conocimiento el usuario final", explican.

\section{BENEFICIOS}

La IA permite extraer conocimiento a partir de texto libre y poner este conocimiento en 
modelos que pueden ser utilizados por el médico, lo que da lugar a la medicina de precisión. "El ser humano tiene capacidad para manejar entre 4 y 5 variables al mismo tiempo. Más es imposible, por lo que cuando un profesional de la Medicina hace un diagnóstico se basa sobre el patrón generado en su cerebro basado en la experiencia", indica José María Martínez, responsable de IA en Santa Barbara Smart Health.

"El beneficio de la IA", explica Martínez, "es que la empresa cuenta con una herramienta que se considera inteligente porque es mucho más flexible que un software basado en una programación determinista. La IA emula al cerebro humano e intenta aprender a partir de una interacción con los datos suministrados. Con ellos, es con los que posteriormente, en base a estadística, establece patrones. El hecho de contar con millones de datos es que los modelos extraídos por la IA son más robustos y precisos".

"De momento, desde la creación de Santa Barbara, todavía no hemos terminado un producto comercial que esté implantado en clínicas u hospitales. Eso sí, estamos cerca de acabar un prototipo para el año que viene poder testearlo en práctica clínica. Este es el motivo por el que todavía no podemos dar una cifra de eficiencia de nuestros desarro"los", explica José María Martínez.

"No debe olvidarse ", matiza, "que estamos tratando con información médica de pacientes, la información más sensible y más protegida por las normas de protección de datos. Por ello, son numerosos los procedimientos de control que nos realiza Fresenius, siempre para garantizar el anonimato de los enfermos".

Asimismo, indican que, a nivel económico, el desarrollo de IA requiere un gasto en recursos (servidores y software), "aunque también es cierto que un número considerable de los mismos es open source”, explican. El siguiente paso, augura Carlo Barbieri, será el del paciente como usuario final. "En un futuro quien aplicará el conocimiento que ofrece la IA será directamente el paciente".

\section{RECOMENDACIONES PARA EMPRESAS QUE QUIERAN DEDICARSE A LA IA}

Son varios los aspectos que Carlo Barbieri considera imprescindibles a la hora de constituir la empresa.

\section{1) EL EQUIPO}

"El tesoro más grande de cada equipo de IA son las personas. Cuánto mejor preparadas, válidas y motivadas, mayores serán las probabilidades de éxito. Este no es un trabajo rutinario, sino que requiere ser creativo y la capacidad de afrontar desafíos, pues no todos los procesos están definidos al 100\%".

\section{2) LA TECNOLOGÍA}

"El contacto con la universidad y con el conocimiento científico es clave para este tipo de empresas, que requieren constante actualización. Las instituciones académicas, al estar menos orientadas a la obtención de resultados concretos -lo que precisamente le urge a la empresa- pueden estar al día de las últimas novedades. 
Además, son la puerta de acceso al talento. De hecho, debido a la elevada demanda de este tipo de profesional se ha creado el Grado en Ciencia de Datos. En ella, la IA es una parte específica para elaborar modelos inteligentes.

\section{3) CONTACTO CON EL NEGOCIO/REALIDAD}

"Se debe intentar mantener un contacto entre el negocio y la parte científica de desarrollo de IA. Puedes desarrollar el modelo más atractivo, pero puede darse el hecho de que no sea aplicable en el día a día. Aunque recomiendo que se lleve a cabo en un departamento separado a los procesos normales de la empresa, debe existir un contacto con el modelo de negocio, con alguien que entienda el mercado y que sea capaz de crear nuevas líneas de mercado en base a los modelos desarrollados. El objetivo final es desarrollar un sistema que finalmente alguien utilice en la práctica". 


\title{
2. DEEP-LEARNING:
}

NOUSS INTELLIGENCE

\section{NOUS S}

\author{
Año de creación: 2017 \\ Misión: Spin-off de desarrollos de inteligencia artificial aplicados a la organización industrial \\ Equipo de profesionales: 5 científicos de Inteligencia Artificial, 8 tecnólogos y dos gestores \\ profesionales
}

Ubicación: Parque Científico de la Universidad de Alicante

El germen de esta compañía alicantina radica en un convenio de colaboración firmado en 2014 entre la Universidad de Alicante y Rosmiman Software Corporation, empresa privada que dispone de una de las suites más completas de software para la automatización del mantenimiento, la gestión de activos y el facility management. En concreto, la empresa firmó un convenio con el Departamento de Tecnología Informática y de Computación (DTIC) para dotar de inteligencia a la planificación de las órdenes de trabajo y los recursos necesarios para la ejecución de los servicios.

El convenio dio como fruto el sistema que solicitaba la empresa, pero el equipo investigador involucrado, el grupo I2RC (Grupo de Investigación de Informática Industrial y Redes de Computadores), decidió desarrollar un motor más versátil, que pudiera utilizarse para otros fines, partiendo de un núcleo común de rutinas y algoritmos. En el proyecto trabajaron el catedrático Juan Manuel García Chamizo; los profesores titulares Jerónimo Mora Pascual y Javier Ferrández Pastor; y dos profesores asociados, Oscar Marin Alonso y Rafael Valdivieso Sarabia. Sin ser científicos de Inteligencia Artificial propiamente, los cinco son especialistas en programación de tareas dentro de procesadores, especialmente para la optimización de los mismos.

Tres años después, en marzo de 2017, el equipo investigador consideró conveniente crear una empresa de base tecnológica que permitiera llevar adelante la explotación comercial de los algoritmos creados para resolver problemas reales en la industria, esto es, para organizar recursos y planificar tareas de modo eficiente. Tendrían que dotarla de medios y actividad comercial real. "Y fue en ese momento cuando contactaron conmigo", explica Fernando Guerrero, CEO desde entonces de Nouss Intelligence. Los motivos del fichaje era su experiencia en gestión empresarial. Además de Nouss, es el cofundador y hoy presidente no ejecutivo de la empresa tecnológica internacional SolidQ. 


\section{LA UA COMO SOCIO}

Los motivos que, según Fernando Guerrero, le impulsaron a unirse al proyecto como socio y director general fueron dos:

1) El rigor de la Universidad de Alicante a la hora de desarrollar motores de Inteligencia Artificial

2) Sus efectos prácticos, es decir, su aplicación comercial muy concreta, "pues directamente ahorra costes a cualquier empresa que se aplique".

"El impulso al proyecto lo dio, indudablemente, la Universidad de Alicante, que es también socia de la empresa. Es quien autoriza la transferencia del know how del grupo I2RC a esta spin-off", subraya Guerrero. Junto a ella, los socios fundadores son los cinco profesores y Fernando Guerrero como único socio fundador externo a la institución académica.

La colaboración pública-privada tiene lugar en el Parque Científico de la Universidad de Alicante, donde están instalados. "El PCUA nos permite estar pegados a la universidad, no solo en sentido físico, sino además porque permite el intercambio: por un lado, los profesores que son socios de Nouss Intelligence y que trabajan en la universidad, pueden acceder rápidamente a la empresa; y, por otro lado, el personal que contratamos, con inquietudes en investigación, pueden participar de la formación y las actividades docentes de la institución académica. Además, en general, podemos acceder al fondo bibliotecario de revistas científicas, el cual es imprescindible para asegurarnos que estamos en el límite del último conocimiento".

Paralelamente, "también es importante devolver a la universidad todo el conocimiento que nos transfiere y que nos permite conseguir nuestros desarrollos. Por ello, hemos establecido convenios para que estudiantes de grados y másteres hagan prácticas en la empresa y puedan acceder luego a un trabajo remunerado. Asimismo, participamos en actividades de investigación de la institución académica. La nuestra es una relación bidireccional, donde hay un flujo natural de conocimiento entre la universidad y la empresa".

\section{"Es importante devolver a la universidad todo el conocimiento que nos transfiere y que nos permite conseguir nuestros desarrollos"}

"El hecho de que una empresa surja de una idea generada en la universidad no implica que tenga que ubicarse en un parque científico. Depende de su voluntad de seguir generando conocimiento. Y una no es mejor que la otra, sino que son empresas con objetivos distintos. Las empresas que se instalan en un parque científico son aquellas que realmente tienen intereses en seguir avanzando en el conocimiento de la mano de la universidad e invirtiendo en I+D", sostienen. 


\section{¿CÓMO FUNCIONA NOUS INTELLIGENCE?}

El nombre Nouss deriva de la la palabra griega noéin que significa mente, espíritu, inteligencia, sentido. La aproximación inicial al cliente no es mediante una fuente de datos generada previamente, sino que, partiendo de cero, se intenta capturar la experiencia y conocimientos de las personas que mejor conocen la empresa, directivos que saben cómo se organizan las tareas. Dicho conocimiento genera una serie de algoritmos.

"Lo que intentamos es entender, desde el punto de vista de la empresa, sus criterios de optimización en cada momento", explica el CEO: "Nuestros algoritmos se basan en la experiencia de los expertos en la empresa. Posteriormente, con el uso, sí que se definen patrones a medida que vamos capturando el uso de los trabajos, y es en este momento cuando los motores pueden detectar relaciones que no eran evidentes en el principio". En el caso de que la empresa cuente con un historial de datos se pueden incorporar como una fuente de información adicional.

\section{"Lo que intentamos es entender, desde el punto de vista de la empresa, sus criterios de optimización en cada momento"}

Por tanto, frente a la estrategia del Machine-Learning, que elabora pronósticos a partir de la inferencia de datos de la realidad, Nouss solo desarrolla motores de IA que funcionan a partir del conocimiento extraído de la propia experiencia en la empresa.

"Lo que intentamos es, primero, escuchar los problemas del cliente, qué tipo de actividades realiza y qué es lo que le hace perder dinero o cuota de mercado. Cuando conoces sus deficiencias, puedes empezar a pensar hasta qué punto un motor de IA podría mitigar esos problemas. Aquí es cuando, con nuestra experiencia, sobre todo si hemos trabajado anteriormente en un caso similar, podemos estimar más o menos si el motor les sería útil o no. Si se ve que el motor no mejorará los problemas identificados, no tiene sentido desarrollarlo; sería un juguete que, como entretenimiento, estaría muy bien, pero

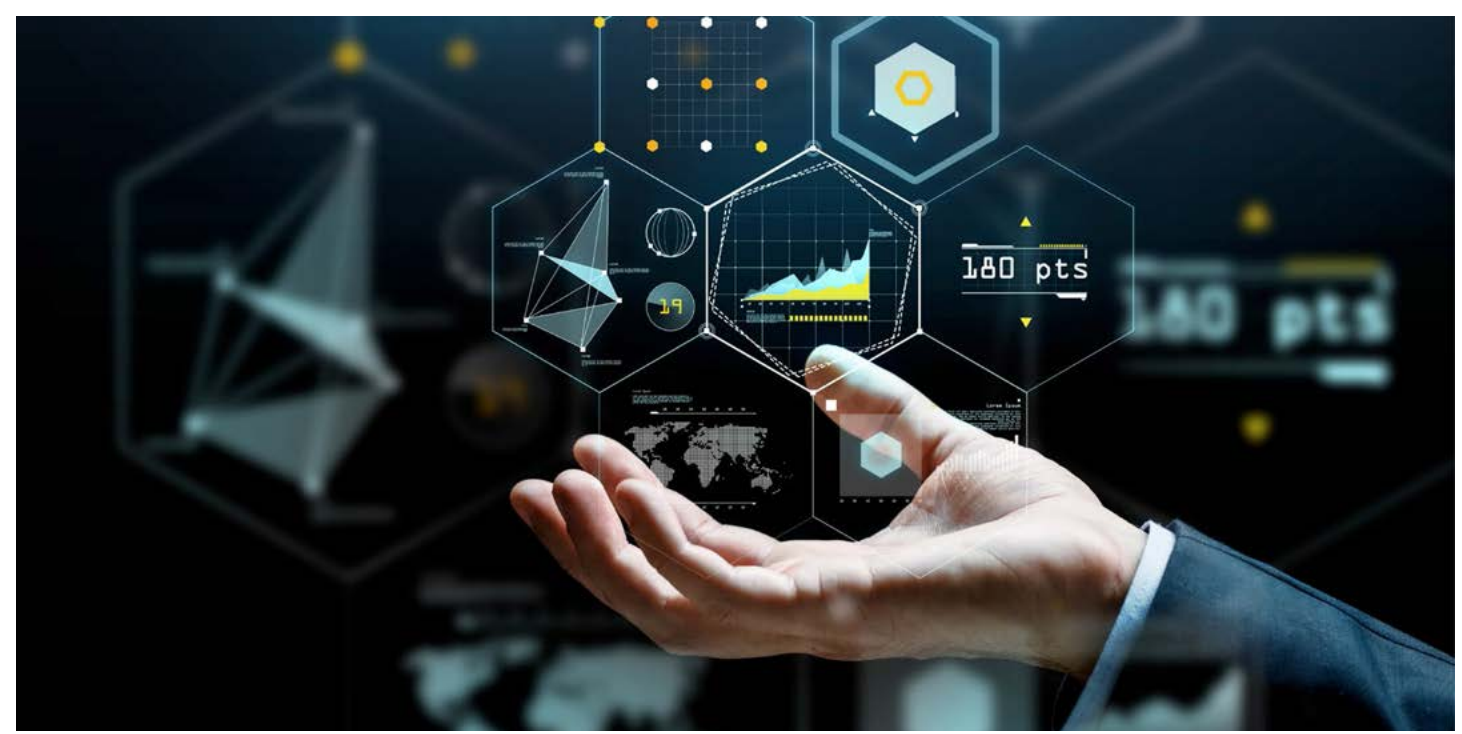


desde el punto de vista empresarial no tendría sentido".

Para llevar a cabo el desarrollo del motor, el primer paso es conocer cuál es el modelo de negocio, cómo se asignan recursos, en base a qué, porqué unas tareas son más prioritarias que otras. "Es información valiosa que solo el experto conoce. Su marcha repentina puede dejar a la empresa sin un activo muy importante que no es sencillo reemplazar. Para evitarlo, Nouss trata de trasladar esa información dentro de los motores de IA. Además, con estas variables informatizadas, a la empresa le será más fácil captar nuevo talento sin los sesgos normales que suelen aparecer cuando una persona humana planifica", explica Fernando Guerrero.

Tras el volcado de información y atendiendo siempre a los criterios de optimización de la empresa (minimizar tiempo, minimizar costes, la utilización lógica de un recurso limitado, la priorización de clientes), el motor aplicará patrones. Sin embargo, si detecta que el sistema no es óptimo, lo corregirá.

\section{LAS INCIDENCIAS}

En el funcionamiento diario el motor va indicando las tareas a realizar por cada empleado/a. Puede hacerlo a través del teléfono móvil o un panel en una sala general donde trabaja el personal. "No tiene que preocuparse en organizar toda la jornada. Se centra en la tarea señalada, y en función de cómo se va llevando a cabo, el sistema recalcula tiempo, modo y quién tienen que hacer la siguiente tarea", explica la empresa.

En el día a día de las compañías acontecen sucesos que rompen la planificación (una máquina se rompe, una persona enferma) y es "en estos casos donde se observa el potencial del motor, que es más productivo que los técnicos que se dedican a planificar. El motor determinará cómo desviar tareas ya asignadas a una persona para que las ejecuten otras", aseguran desde Nouss Intelligence.

\section{EQUIPO HUMANO}

La plantilla de Nouss Intelligence está formada fundamentalmente por ingenieros informáticos e ingenieros multimedia, muchos de ellos con estudios de postgrado, y algunos de ellos ya doctorados o en proceso de realizar su doctorado en Informática, con foco en tecnologías relacionadas con la IA.

"Podría llamar la atención la incorporación de Ingenieros Multimedia a un equipo de desarrollo de IA. La realidad es que en el diseño de videojuegos se utiliza mucha IA. En muchos juegos encontramos una serie de personajes que están gestionados por un motor de IA, el cual trabaja para que la interacción con el usuario sea lo más gratificante posible", indica Fernando Guerrero.

Otros profesionales clave en este tipo de proyectos son los matemáticos, así como los arquitectos de software. "Nuestros motores de Inteligencia Artificial funcionan en la nube, 
pero además de almacenar allí el motor, debes configurar como interactúa el motor con las distintas aplicaciones del cliente, siempre primando que la conexión sea eficiente, escalable y tolerante a fallos".

A pesar de este equipo de tecnólogos, el éxito de Nouss Intelligence, que no deja de ser una entidad mercantil, sólo es posible si los desarrollos técnicos se acompañan de un importante esfuerzo comercial. "Para cubrir esta faceta de nuestro negocio, incorporamos a un socio inversor en noviembre del año pasado, quien ha cubierto el puesto de Director Comercial de Nouss, aprovechando su amplia experiencia comercial, así como su red de contactos. Además colaboramos con tres comerciales freelancers que nos ayudan a identificar nuevas oportunidades", apuntan.

\section{RESULTADOS}

Dado que la empresa tan solo tiene poco más de un año de vida, no hay historia suficiente para hacer cálculos de resultados de forma fiable. Al respecto, Guerrero afirma que "aunque el incremento de productividad varia del 10 al 40\%, tenemos muy poco tiempo de vida para asegurar que son mejoras sostenibles en el tiempo. No olvidemos que nuestra forma de trabajar radica, al principio, de la captación de la experiencia de expertos, pero, luego, el motor va añadiendo datos de la gestión diaria y va aprendiendo".

En este sentido, el CEO de Nouss Intelligence pone como "ejemplo muy típico" el hecho de que los clientes quieran empezar a implantar el motor de gestión de forma muy gradual. "Van saturados de trabajo, y como no disponen de tiempo para introducir toda la información de la empresa, van poco a poco por departamentos".

\section{ACTUALES CLIENTES}

Dentro de una cartera compuesta por una decena de clientes de tipología variada, Acciona Servicios es la empresa más grande para la que trabajan en 2018, año en que se edita este libro electrónico. "Cuentan con una plantilla de 20.000 trabajadores; sin embargo, hemos empezando gestionando el trabajo de unas cuantas decenas dedicadas a un determinado proyecto a optimizar. Progresivamente iremos cubriendo más y más contratos que ellos tienen con sus clientes", explica Guerrero.

También están trabajando para una empresa de distribución de paquetería. El objetivo del motor en este caso es optimizar las rutas de sus operarios. Lo mismo ocurre con un restaurante piloto en Alicante, de un tamaño medio de 50 empleados, para el que están diseñando un sistema para optimizar las tareas de cocina, sala y gerencia.

A ello hay que sumar el desarrollo de un motor de IA para la gestión del "metro de una gran ciudad española y de una fábrica bastante conocida de coches”, apuntan sus responsables. "Cada vez que hablamos con un cliente y les explicamos las mejoras de nuestros motores, siempre se muestran receptivos, pero nos piden tiempo para encajar el proyecto en su planificación de inversiones. Lo aplazan especialmente por la dedicación de personal que deben destinar para implantar el sistema. Normalmente nos suelen 
acompañar en este proceso el director de Informática o el de Tecnologías".

El modelo de negocio se basa en la venta de software como servicio: "No cobramos una cantidad grande por utilizar sistema, sino que lo que hacemos es cobrar una licencia mensual por el uso. Con ella amortizamos la inversión previa para diseñar el sistema, así como la mejora continua del sistema y el soporte al cliente".

\section{INVERSIÓN EN I+D}

La inversión realizada de julio de 2017 a julio de 2018 por la empresa se cifra en 250.000 euros, cantidad que se ha destinado a mejorar el rendimiento de los motores y a hacerlos "más escalables, seguros y tolerantes a fallos", sostiene su director: "A fecha de septiembre de 2018, en lo que queda de año invertiremos además en torno a 75.000 euros. Nos hemos dedicado principalmente a la inversión. La facturación empezará a consolidarse en el último trimestre de 2018".

Para arrancar han contado con el apoyo del Programa CREATEC de Instituto Valenciano de Competitividad Empresarial (IVACE) así como con la inyección financiera del Banco Sabadell. "Lo importante no son las subvenciones, sino tener fondos, aunque sean préstamos; si la empresa tiene éxito, devolverá esos fondos a la sociedad", asegura Fernando Guerrero: "Lo que no interesa son subvenciones con plazos de adjudicación tan dilatados que quitan el sentido a la ayuda".

\section{¿QUÉ CONSEJOS DARÍA A UNA STARTUP QUE QUIERA BASAR SU MODELO DE NEGOCIO EN INTELIGEN- CIA ARTIFICIAL?}

Al respecto, Fernando Guerrero indica que las empresas de estas características deben suplir las siguientes condiciones básicas:

1) Deben tener presente que únicamente con la tecnología de IA no se monta una empresa. El proyecto debe partir teniendo cubiertos aspectos legales, laborales, económicos y financieros, pues si alguno no funciona correctamente, puede llevar la empresa al traste.

2) Una empresa vive del dinero que gana, por lo que hay que saber cómo se van a comercializar los servicios, directamente o mediante distribuidores, y contar con profesionales con experiencia en estos campos. "Y en este punto haré hincapié en un aspecto muy importante, la financiación. Es fundamental que se valore el trabajo que se está invirtiendo y el que se va a realizar para que se tenga claro que se dispone de los fondos necesarios para poner la empresa en marcha y hacer flujo de caja".

3) Desde punto de vista tecnológico, "ahí cada cual tiene sus objetivos. Pienso que hay muchas apps de IA que podrían resolver problemas concretos de una inmensa mayoría de empresas, pero también hay muchos casos en los que detecto empresas nuevas que pretenden resolver situaciones difíciles de monetizar. Por 
ejemplo, hay aplicaciones de la IA enfocadas al reconocimiento de voz o de imágenes, o a la interacción humano-máquina, que no representan oportunidades de monetización inmediatas, a pesar de que sientan los cimientos para avances tecnológicos importantes. Son los desarrolladores de cada empresa los que pueden utilizar esos avances e implantarlos para cada necesidad. Personalmente, como ingeniero, pienso las cosas de manera pragmática. Y, en mi opinión, los desarrollos deben tener una aplicación real que nos permita decirle al cliente cuánto dinero va a ganar de más y cómo le va a afectar a sus cuentas de resultados. Me gusta que mis empresas se dediquen a desarrollar sistemas y proyectos que mejoran la rentabilidad de mis clientes". 


\section{¿Tienes una idea innovadora y necesitas asesoramiento?}

¿Quieres impulsar tu proyecto científico 0 tecnológico con éxito?

\section{¿Buscas un espacio de emprendimiento en una ubicación privilegiada?}

\footnotetext{
El Parc Científic de la Universitat de València es mucho más que un lugar de trabajo. Aprovecha todas las ventajas de un ecosistema de innovación y transferencia de conocimiento único.
}

SERVICIOS A LAS EMPRESAS

¿CÓMO INSTARSE EN EL PARC?

CONTACTA CON NOSOTROS 
PAR C CIEN TÍF I C

VNIVERSITATợ DQ VALĖNCIA

Coordinadora de la edición: María Iranzo

Con el apoyo de

\section{GENERALITAT VALENCIANA}

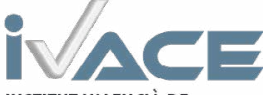

